\title{
Cleaving automatic processes from strategic biases in phonological priming
}

\author{
JAMES M. MCQUEEN \\ Max Planck Institute for Psycholinguistics, Nijmegen, The Netherlands \\ and \\ JOAN SERENO \\ University of Kansas, Lawrence, Kansas
}

\begin{abstract}
In a phonological priming experiment using spoken Dutch words, Dutch listeners were taught varying expectancies and relatedness relations about the phonological form of target words, given particular primes. They learned to expect that, after a particular prime, if the target was a word, it would be from a specific phonological category. The expectancy either involved phonological overlap (e.g., honk-vonk, "base-spark"; expected related) or did not (e.g., nest-galm, "nest-boom"; expected unrelated, where the learned expectation after hearing nest was a word rhyming in - alm). Targets were occasionally inconsistent with expectations. In these inconsistent expectancy trials, targets were either unrelated (e.g., honk-mest, "base-manure"; unexpected unrelated), where the listener was expecting a related target, or related (e.g., nest-pest, "nest-plague"; unexpected related), where the listener was expecting an unrelated target. Participant expectations and phonological relatedness were thus manipulated factorially for three types of phonological overlap (rhyme, one onset phoneme, and three onset phonemes) at three interstimulus intervals (ISIs; 50, 500, and 2,000 msec). Lexical decisions to targets revealed evidence of expectancy-based strategies for all three types of overlap (e.g., faster responses to expected than to unexpected targets, irrespective of phonological relatedness) and evidence of automatic phonological processes, but only for the rhyme and three-phoneme onset overlap conditions and, most strongly, at the shortest ISI (e.g., faster responses to related than to unrelated targets, irrespective of expectations). Although phonological priming thus has both automatic and strategic components, it is possible to cleave them apart.
\end{abstract}

Analysis of the component processes involved in spoken-word recognition is critical for the development of theories of spoken language understanding. A primary distinction that must be made in such an analysis is one that has had a long history in cognitive psychology: the distinction between automatic and controlled processes (Neely, 1977; Posner \& Snyder, 1975; Schneider \& Shiffrin, 1977; Shiffrin \& Schneider, 1977). In the context of speech processing, this distinction can most simply be formulated as that between automatic perceptual processes, which act upon the information in the speech signal whenever listeners hear their native language, and controlled attentional processes, which listeners can bring to bear as they respond to the demands of particular listening situations. The listening situation we investigate here is a phonological priming experiment in which we attempted to

This research was supported in part by visiting scholarships from the Max-Planck-Gesellschaft to the second author. We thank Tau van Dijck, Allard Jongman, Anne Rutgers, Anne Pier Salverda, Michiel Seevinck, Keren Shatzman, and Edith Sjoerdsma for their assistance with different stages of this project and two anonymous reviewers for comments on a previous version of this article. Please address correspondence to J. M. McQueen, MPI for Psycholinguistics, Postbus 310, 6500 AH Nijmegen, The Netherlands (e-mail: james.mcqueen@mpi.nl or sereno@ku.edu). separate the automatic phonological processes that are involved in word recognition from expectancy-based strategies that listeners can use in response to the experimental task.

Priming methodologies have been used extensively to investigate the processing involved in word recognition. Priming tasks typically involve a sequence of a prime followed, in close temporal proximity, by a target item. In this methodology, the relationship between the prime and the target is manipulated and often includes overlap along semantic or form-based dimensions. In the present research, we investigated priming effects in the case in which the prime and the target are related in form. In phonological priming experiments, prime and target overlap can involve phonological coincidence at the beginning or at the end of items, and this overlap may consist of a varying number of shared phonemes. The following historical survey of the phonological priming literature illustrates that it is rife with controversy, particularly with respect to the distinction between automatic and strategic processes.

\section{Onset Overlap}

Slowiaczek, Nusbaum, and Pisoni (1987) investigated phonological priming effects involving overlap in onset position. A spoken prime was presented, followed by a 
target item presented in noise. The participants' task was identification of the target. Amount of overlap and signalto-noise ratio were varied. The results showed significant facilitatory priming effects, which increased with increasing phonological overlap and stimulus degradation. But as a hint of future controversies, a second series of experiments in which similar materials were used showed different results (Slowiaczek \& Pisoni, 1986). Although primes facilitated responses to targets when the primes and the targets were identical, no facilitatory priming was observed for primes sharing one, two, or three phonemes from onset at either interstimulus interval (ISI; 50 or $500 \mathrm{msec}$ ). These differences in results were attributed to task differences: The former experiments used identification in noise, and the latter experiments employed auditory lexical decision.

Radeau, Morais, and Dewier (1989) pursued this explanation, examining phonological relatedness in both lexical decision and shadowing (i.e., repetition of the target word), using minimal ISIs, and presenting stimuli in the clear. They claimed that whereas lexical decision was more prone to strategic effects involving response biases (see, e.g., Balota \& Chumbley, 1984), shadowing tasks were not as susceptible to such postaccess processing. In lexical decision, Radeau et al. (1989) observed significant inhibition for prime-target word pairs with one- or two-phoneme overlap. For shadowing, inhibitory effects were also observed, although much reduced in magnitude. These inhibitory effects disappeared when nonword primes were used. Radeau et al. (1989) suggested that the interference effect was an artifact of the design - that is, a lexical decision task that included targets that were identical to their primes. Phonological relatedness was thus claimed to produce interference effects in lexical decision, due to involvement of postlexical strategic checking mechanisms.

The results of Goldinger, Luce, Pisoni, and Marcario (1992) suggest that facilitation due to one-phoneme onset overlap in lexical decision may also be due to strategic processes. In an attempt to distinguish strategic effects from automatic effects, Goldinger et al. systematically manipulated the proportion of related trials (note also that the materials were presented in noise). Goldinger et al. found that one-phoneme facilitatory priming could be attenuated by reducing the proportion of related priming trials from $50 \%$ to approximately $10 \%$ of all trials. In fact, under these conditions, the facilitatory effects became inhibitory. These results led Goldinger et al. to conclude that this type of phonological priming (one-phoneme onset overlap, with lexical decision in noise) appears to be due to a response bias (see also Goldinger, 1998b).

Slowiaczek and Hamburger (1992) used shadowing in order to minimize the influence of strategic bias effects. They found facilitatory priming (faster repetition of targets) in the one-phoneme overlap condition and inhibitory priming (slower repetition of targets) in conditions with greater overlap (two- and three-phoneme overlap). Inclusion or exclusion of an identical priming condition did not affect either of these effects, suggesting that the presence of identical prime-target pairs did not induce an identitybased strategy. Slowiaczek and Hamburger therefore interpreted these results in terms of automatic processes. They proposed that the facilitation was due to excitation at a prelexical phoneme level and that the inhibition was the result of competition between words at the lexical level.

Further research, however, has shown that this conclusion was premature. Hamburger and Slowiaczek (1996), using primed shadowing, contrasted response times (RTs) for conditions with low relatedness proportions and short ISIs with RTs for conditions with high relatedness proportions and long ISIs. They found that one- or two-phoneme overlap resulted in facilitation only in conditions that maximized strategic effects (a high relatedness proportion and a long ISI), whereas three-phoneme overlap consistently resulted in interference, regardless of relatedness proportion or ISI. The low-similarity facilitation thus seems to be strategic, related to participants' expectancies, and distinct from the high-similarity interference, which appears to be automatic and, most likely, due to lexical competition.

In order to ascertain the locus of these priming effects, Radeau, Morais, and Seguí (1995) undertook a study in which frequency relations between the prime and the target were manipulated. If phonological effects involve lexical representations, varying the frequency relations between the prime and the target (high-frequency prime with low-frequency target or the reverse) should influence the amount of priming. They observed no priming or weak unreliable inhibition for word-initial overlap. The effect occurred only in the low-high condition in which the shadowing task and a short ISI were used. Radeau et al. (1995) concluded that the initial inhibitory effects are lexical, rather than a result of response bias.

Goldinger (1999) has reported, however, that even discouraging expectancy effects by using a low relatedness proportion in a shadowing task does not necessarily ensure that response biases are not present. Rather than varying relatedness proportion and examining its effect on the amount of priming in related trials, Goldinger (1999) examined the control trials over time, in order to assess the possible costs associated with avoiding false-positive errors on the unrelated trials. For the high-expectancy, as well as the low-expectancy, condition, RTs to control trials became longer over the course of the experiment, relative to a pure control condition with no related trials. These results suggest that even when procedures minimize strategic influences, response biases cannot be completely removed. But a further aspect of the data tempers this conclusion. Hamburger and Slowiaczek (1996, 1999) showed that the inhibitory effect in shadowing with a three-phoneme onset overlap became stronger as expectancy biases became weaker (i.e., when shifting from high- to low-expectancy conditions). In contrast, the facilitatory effect with a one-phoneme onset overlap disappeared as expectancy biases were reduced. Furthermore, Monsell and Hirsh (1998) found evidence of inhibition due to multiple-phoneme onset overlap under conditions in which strategic effects are likely to be small (in lexical decision in which responses were made on every trial, 
with many intervening items between the primes and the targets). Thus, although it may be impossible to remove all response biases under low-expectancy conditions, it would appear, on the basis of these results, that at least the inhibition observed with multiple-phoneme onset overlap is not due to such biases.

The story does not end there, however. Pitt and Shoaf (2002) recently investigated shadowing latencies for primes and targets sharing three overlapping onset phonemes. As in Goldinger (1999) and Hamburger and Slowiaczek (1999), performance at multiple points during the experiment was investigated. Pitt and Shoaf examined not only the unrelated control trials, but also responses to a subset of related items at different positions within the experimental sequence. Their argument was as follows: If differences were found across position for the related trials, they would be more likely to be due to response biases than to lexical competition (which should be constant over time). Responses to phonologically related prime-target pairs resulted in an initial slowdown that was attributed to a surprise effect (the first target to overlap with a prime being unexpected). This slowdown decreased over time as participants appeared to adopt a response strategy to deal more effectively with prime and target overlap. Pitt and Shoaf claimed that manipulations to discourage biases, such as relatedness proportion or ISI, do not succeed in eliminating them and that sometimes a single related trial can induce such a strategy.

This summary of onset priming research clearly shows evidence of disagreement concerning the nature and locus of the phonological priming effects. A number of consistent findings, however, have emerged from this literature-most important, a listing of variables that affect onset phonological priming. Amount of phonological overlap (i.e., one-, two-, or three-phoneme overlap) can change the direction of the observed priming effect, from facilitation to inhibition. Variation in relatedness proportion, task, and ISI also have been shown to contribute to participants' expectancies within the experimental context, thereby inducing or shaping possible response biases.

A consensus appears to have been reached concerning the facilitation observed when primes and targets share one onset phoneme (e.g., bone-beach). This facilitation appears to be due to strategic processes. In shadowing, the effect depends on a high relatedness proportion (Goldinger, 1999; Hamburger \& Slowiaczek, 1996; Slowiaczek \& Hamburger, 1992). Under these conditions, participants seem to learn that targets often begin in the same way as the preceding primes and, thus, appear to prepare the production of those initial segments, thereby repeating the targets more quickly. In lexical decision, this facilitation has been found only when there was a high relatedness proportion and when stimuli were presented in noise (Goldinger, 1998b; Goldinger et al., 1992). Under these conditions, it appears that participants can use the expectation of a shared initial segment to benefit recognition of the target in the noise.

Controversy remains, however, about the effects of multiple-phoneme onset overlap (e.g., sweep-sweet).
The pattern of results is not consistent. Inhibition with this kind of overlap has been observed in lexical decision (Monsell \& Hirsh, 1998; Radeau et al., 1989; Slowiaczek \& Pisoni, 1986) but has often been statistically nonsignificant (Praamstra, Meyer, \& Levelt, 1994; Radeau et al., 1995). It could be attributed to participant strategies in some cases (Radeau et al., 1989; Slowiaczek \& Pisoni, 1986) but probably not in all (Monsell \& Hirsh, 1998). Likewise, although inhibition has been observed with the same kind of overlap in shadowing (Goldinger, 1999; Hamburger \& Slowiaczek, 1996; Radeau et al., 1989; Slowiaczek \& Hamburger, 1992), and although it has been claimed that this inhibition is due to automatic processes of lexical competition, and not to expectancy strategies (Hamburger \& Slowiaczek, 1996, 1999), the recent findings of Pitt and Shoaf (2002) suggest that it could, after all, reflect expectancy effects and that participants adjust the way they respond to related trials over the course of an experiment. One purpose of the present experiment was, therefore, to disentangle the automatic and strategic components of the inhibitory priming that appears when primes and targets share multiple phonemes at onset.

\section{Offset Overlap}

In addition to phonological priming effects in which prime and target overlap involves coincidence at the beginning of items, overlap can also consist of primes and targets in which there is coincidence at the end of words. It again appears that there are both automatic and strategic effects, given this kind of overlap. In many of the earliest studies, rhyme priming (overlap of the stressed vowel and the rest of the word) was investigated. Unlike the phonological onset literature, studies on offset overlap have consistently shown strong facilitation when targets have been preceded by rhyming primes. Meyer, Schvaneveldt, and Ruddy (1974) found robust facilitation in a visual lexical decision experiment when pairs of words rhymed. Hillinger (1980) and Jakimik, Cole, and Rudnicky (1985) broadened these results to include auditorily presented words, and Burton, Jongman, and Sereno (1996) showed similar effects in a shadowing task.

In order to investigate degree of phonological similarity from word offset, Slowiaczek et al. (1987) varied overlap from one phoneme to three phonemes (traditional rhyme priming). Using a word identification in noise task, Slowiaczek et al. (1987) found that correct identification increased with increasing overlap from offset. Radeau et al. (1995) replicated this consistent pattern of facilitation for two-phoneme final overlap conditions. They further observed only minimal reduction of the facilitation at longer ISIs and in a shadowing task, whereas there was no effect of prime-target relative frequency on the priming effects, encouraging them to conclude that final overlap phonological priming effects are due to automatic prelexical processes and that these effects are impervious to the influence of strategic bias.

Slowiaczek, McQueen, Soltano, and Lynch (2000) explicitly tested this claim by varying relatedness proportion and simultaneously increasing phonological overlap from 
offset. Although their data, in general, show increased facilitation for increasing overlap conditions, high relatedness proportions did produce greater facilitation, and responses to unrelated trials tended to become slower later in the experiment, both of which suggest weak strategic components. Slowiaczek et al. (2000) argued, however, that although nonrhyming overlap can produce facilitation, presence of rhyme overlap, rather than absolute or proportional amount of segmental overlap, is the best predictor of the priming effects. Slowiaczek et al. (2000) concluded that final overlap phonological facilitation can be accounted for by two processes: automatic activation of prelexical perceptual representations and a bias based on the salience of rhyme overlap.

Norris, McQueen, and Cutler (2002) showed reliable rhyme priming effects in auditory lexical decision for word targets. When foils were included (i.e., trials in which targets almost rhymed with their primes, which were meant to discourage use of a response strategy), the facilitatory rhyming effects were attenuated, suggesting that an important component of this facilitation is strategic. In a similar set of experiments with shadowing, however, although there was some reduction in the amount of priming when foils were included, these differences were not significant. Both word and nonword targets showed similar facilitatory priming, which did not change significantly in the presence of foils. Norris et al. therefore suggested that, in addition to the strategic component of rhyme priming seen in lexical decision, there exists a component that is nonstrategic and that appears to be due to automatic processing, which operates prior to lexical access. That is, there appears to be some benefit from the fact that the prime and the target activate the same prelexical representations.

The offset priming research thus shows consistent evidence of facilitation (see also Dumay et al., 2001; Emmorey, 1989; Monsell \& Hirsh, 1998; Praamstra et al., 1994; Radeau, Besson, Fonteneau, \& Castro, 1998; Spinelli, Seguí, \& Radeau, 2001; Titone \& Connine, 1997). Increasing the amount of phonological overlap (one-phoneme, two-phoneme, or three-phoneme overlap) significantly increases the amount of facilitation observed, but this increase seems to be mediated by whether the overlap constitutes a rhyme. Variations in relatedness proportion, task, and ISI have been shown to influence the priming effects much less than in onset priming, thereby supporting the notion that final overlap facilitation reflects automatic prelexical processes. The absence of offset overlap facilitation in cross-modal versions of the task-both when there is an auditory prime and a visual target (Spinelli et al., 2001) and when there is a visual prime and an auditory target (Dumay et al., 2001) — supports the view that the locus of these automatic processes is within the speech-processing system. Furthermore, the repeated demonstration that facilitation of responses to rhyming word targets is equivalent after word and nonword primes (Dumay et al., 2001; Monsell \& Hirsh, 1998; Slowiaczek et al., 2000) confirms that the locus of the automatic processes is prelexical. Most authors have, therefore, assumed that rhyme-based facilitation reflects the repeated activation of prelexical representations: The processing of the target is facilitated because its recognition involves the use of many of the same prelexical representations as were activated when the rhyming prime was heard (see, e.g., Slowiaczek et al., 2000). Nevertheless, there is also clear evidence of a strategic component to rhyme-based facilitation. In lexical decision, there is no facilitation on rhyming trials in the presence of foil trials that discourage a rhyme-based strategy (Norris et al., 2002).

\section{Adapting Neely (1977) to Phonological Priming}

Despite the large number of phonological priming studies in the past 2 decades, a number of questions remain unanswered. First, with respect to multiple-phoneme onset overlap, is the inhibition that can sometimes be observed due to automatic or controlled processes? Second, with respect to rhyme overlap, if the facilitation is due, at least in part, to automatic processes, why is it absent in lexical decision when strategic biases have been controlled for? Third, more generally, why is this automatic facilitation not detected with one- or multiple-phoneme onset overlap? In the present experiment, we sought to answer these questions.

It should be clear from the above review that the pattern of phonological priming depends on the position and degree of overlap between primes and targets. We therefore separately examined rhyme overlap, one-phoneme onset overlap, and three-phoneme onset overlap. With respect to word-final overlap, robust phonological facilitation appears to depend, primarily, neither on the absolute number of overlapping phonemes nor on the proportional segmental overlap but, instead, on whether primes and targets rhyme (Slowiaczek et al., 2000). Related primes and targets in the final-overlap condition therefore rhymed with each other. Furthermore, because all the items were monosyllabic, overlap in syllabic structure between rhyming primes and targets was controlled: All the rhyming pairs shared exactly their rime (i.e., nucleus plus coda). In all cases, the overlap consisted of three phonemes (i.e., the vowel nucleus plus two coda consonants), such that both absolute and proportional segmental overlap was also controlled.

For direct comparison with the rhyme overlap condition, we also tested the effects of three-phoneme onset overlap. In this condition, absolute and proportional segmental overlap was again controlled, as was overlap in syllabic structure (two onset consonants plus the vowel nucleus). As was discussed above, multiple-phoneme onset overlap can result in inhibitory priming effects, at least under some conditions. The present design allowed us to test for these effects, using a degree of phonological overlap that was closely matched in syllabic and segmental structure to that used in the rhyme overlap condition. Finally, we examined the case of one-phoneme onset overlap, for which facilitatory effects have previously been observed. Segmental overlap (both absolute and propor- 
tional) was again matched between conditions, as was syllabic structure overlap (primes and targets always shared their onsets; one onset consonant in each case).

It should also be clear from the preceding review that a satisfactory account of phonological priming will depend on distinguishing between automatic and strategic components of the priming effects. In previous studies, strategic involvement has been tested by examining the time course of performance over the duration of an experiment (e.g., Goldinger, 1999; Pitt \& Shoaf, 2002) or by manipulations that were intended to increase or decrease the use of particular strategies (e.g., Goldinger et al., 1992; Hamburger \& Slowiaczek, 1996; Norris et al., 2002; Radeau et al., 1989). In the present study, we took a different approach. We attempted to induce the operation of an expectancybased strategy and then test for effects of phonological overlap on lexical decision both when the expectations of the learned strategy were met and on occasional unexpected trials. We thus hoped to be able to cleave automatic and strategic effects apart. Crucially, this manipulation allowed us to test for automatic effects despite the simultaneous operation of expectancy strategies. Thus, for example, would there be evidence of automatic facilitation with rhyme overlap? It is possible that Norris et al. (2002) failed to detect reliable facilitation with rhyme overlap in lexical decision in the presence of foils because the facilitation was masked by strategic effects (i.e., although the foils may have blocked the operation of a bias to respond yes when targets rhymed with their foils, their presence could have induced a checking strategy). The use of unexpected but phonologically related trials in the present design should allow automatic effects to be measured even in the presence of an expectancy strategy.

The factorial manipulation of relatedness and expectancy has been used successfully in the domain of semantic priming (Neely, 1977). In its simplest form, semantic priming refers to the finding that participants respond more quickly to a target word (e.g., doctor) when it is preceded by a related prime word (e.g., nurse), as compared with an unrelated control (e.g., bread; Meyer \& Schvaneveldt, 1971). Much of the early research on semantic priming attributed the observed facilitatory semantic priming effects to the automatic cognitive mechanism of spreading activation (e.g., Schvaneveldt \& Meyer, 1973). Additional research, however, suggested that some of the priming effects may involve attentional, strategic processing (e.g., Posner \& Snyder, 1975).

In a novel and theoretically pivotal semantic priming experiment, Neely (1977) attempted to cleave automatic spreading activation from limited-capacity attentional mechanisms. To unconfound these mechanisms, Neely separately manipulated two variables. First, the prime and the target were either semantically related or unrelated, in order to assess the automatic activation that was assumed to spread between preexisting semantically related primes and targets. For example, for a given semantic category prime, bird, participants expected a target to be chosen from the same category, such as robin, resulting in a prime-target pair such as bird-robin. Second, par- ticipants' conscious attention was manipulated by varying whether the target was expected given the prior prime word. To accomplish this, a priming word that was semantically unrelated to the target item was used to direct the participants' attention to an expected target item. For example, some categories such as body were consistently associated with exemplars from a different category, such as building parts, resulting in a prime-target pair such as body-door. Expected prime-target pairs, where attention was directed, were contrasted to unexpected prime-target combinations. Using relatedness and expectancy, Neely contrasted four basic conditions: expected-related (ER) conditions such as bird-robin, expected-unrelated (EU) conditions such as body-door, unexpected-related (UR) conditions such as body-heart, and unexpected-unrelated (UU) conditions such as body-sparrow or bird-arm. Both relatedness and expectancy were modulated by a temporal manipulation, stimulus onset asynchrony (SOA). At short SOAs, priming effects that reflected automatic spreading activation were predominant. At longer SOAs, when there was enough time to engage attention, priming effects reflected the slower limited-capacity attentional mechanisms.

Neely (1977) thus succeeded in separating automatic priming from attentional strategies within the semantic domain. The present experiment applied this methodology to the phonological domain. Dutch listeners made lexical decisions to Dutch words and nonwords, which were preceded by limited sets of prime words. Through instructions and practice trials, the participants learned to expect, after specific primes, that targets, if they were words, would have a particular phonological form. Thus, in the case of rhyme overlap (see Table 1), the listeners could learn to expect that the targets would be words if they rhymed, for example, with the prime honk ("base"). In the critical phase of the experiment (i.e., after the expectation had been learned), the targets would either match that expectation (ER trials; e.g., honk-vonk) or mismatch the expectation (UU trials; e.g., honk-mest). In addition, the listeners learned phonologically unrelated expectations (e.g., they learned to expect words that rhymed with -alm after the prime nest, "nest"). Again, the targets could either match or mismatch this expectation, generating EU (e.g., nest-galm) and UR (e.g., nest-pest) trials.

On the basis of the previous literature on rhyme priming, we expected to observe automatic facilitation (i.e., faster and/or more accurate responses on related trials than on unrelated trials) and expectancy biases (i.e., faster and/or more accurate responses on expected than on unexpected trials). We also manipulated the amount of time between primes and targets (ISIs of 50,500, and $2,000 \mathrm{msec}$ ). Because the facilitation due to repeated activation of the same prelexical representations by the prime and the target should decay over time, we predicted that the automatic effect would be strongest at the shortest ISIs. We also predicted that the expectancy bias would be strongest at the longest ISIs, for three reasons: because the listeners would have more time to apply an expectancy strategy, because the relevant information would appear 
Table 1

Experimental Conditions, With Examples for Each Subexperiment

\begin{tabular}{lllc}
\hline & $\begin{array}{c}\text { A: Rhyme } \\
\text { Overlap }\end{array}$ & $\begin{array}{c}\text { B: One-Phoneme } \\
\text { Onset Overlap }\end{array}$ & $\begin{array}{c}\text { C: Three-Phoneme } \\
\text { Onset Overlap }\end{array}$ \\
\hline Exime-Target Relationship & honk-vonk & zeep-zoon & knak-knap \\
Expected-unrelated (EU) & nest-galm & wieg-poes & trog-slim \\
Unexpected-related (UR) & nest-pest & wieg-worst & trog-trom \\
Unexpected-unrelated (UU) & honk-mest & zeep-wijs & knak-tros \\
\hline
\end{tabular}

late in the primes and the targets, and because the expectancy bias could not be used by the listeners to predict how the targets would begin.

Other groups of listeners learned expectancies about the first phoneme of the targets based on the first phoneme of the primes (one-phoneme onset overlap; see Table 1). Given the consensus in the literature that the facilitation that can be observed when primes and targets share one onset phoneme is due to expectancy biases alone, we predicted that under these conditions, there would be no automatic effects (i.e., responses to related targets that were equivalent to those to unrelated targets). An expectancy bias (i.e., responses to expected targets would be faster and/or more accurate than those to unexpected targets) was predicted. This expectancy bias should be strongest at the longest ISIs, because the listeners would have more time to apply the strategy.

Yet other groups of listeners took part in the threephoneme onset overlap conditions (see Table 1). It was difficult to make strong predictions about the results of this subexperiment, because of the confusion in the past literature on multiple-phoneme onset overlap. The results of Pitt and Shoaf (2002), but not those of Hamburger and Slowiaczek $(1996,1999)$, suggest that there should again be expectancy biases (i.e., responses to expected targets that were faster and/or more accurate than those to unexpected targets). As with the other types of phonological overlap, we should also perhaps expect to see stronger expectancy effects at longer ISIs. Automatic effects are more complex. One possible outcome was that there would be facilitation (i.e., better performance on related than on unrelated targets), as was predicted for rhyme overlap. Although facilitation with multiple-phoneme onset overlap has not been observed before, this could be because it was masked by inhibitory expectancy biases. Under the present conditions, however, where it ought to be possible to separate automatic from strategic processes, and where there was as much phonological overlap as in the rhyme overlap subexperiment (three phonemes in each case), it was possible that automatic facilitation would be detected. An alternative outcome was that there would be automatic inhibition (i.e., performance better on unrelated than on related targets). This would be consistent with results in some of the preceding literature (e.g., Hamburger \& Slowiaczek, 1996; Monsell \& Hirsh, 1998) and could be explained in the same way - namely, that it was due to competition between activated lexical hypotheses. If participants are led to expect a target with an onset slithat is phonologically unrelated to the onset of the prime tro- (e.g., prime-target pairs such as trog-slim, "trough- clever"), and if there is evidence that listeners are using this expectation to benefit performance on expected trials, inhibition on UR trials (e.g., trog-trom, "trough-drum") can be taken to be due to lexical competition. A third possible outcome, however, was that there would be neither automatic facilitation nor automatic inhibition. That is, these two effects could cancel each other out. The present experiment, given the control we have over expectancy biases, may therefore give some indication of the relative strength of prelexical facilitation and lexical inhibition in phonological priming with a large amount of initial overlap.

\section{METHOD}

\section{Design}

The experiment involved the between-participants manipulation of the nature of the phonological overlap between primes and targets, forming three subexperiments: (A) rhyme overlap, (B) onephoneme onset overlap, and (C) three-phoneme onset overlap. In all cases, targets were spoken Dutch words or nonwords, and the participants were required to make lexical decisions on those targets. All subexperiments were run in five different versions, each with a different group of participants but each with the same target words. These versions differed with respect to the ISI between primes and targets and with respect to the nature of the control condition. Version 1 (A1, B1, and $\mathrm{C} 1)$ used a $50-\mathrm{msec}$ ISI and an auditory tone as the control prime. Version 2 (A2, B2, and C2) used a 50-msec ISI and phonologically unrelated spoken words as control primes. Version 3 (A3, B3, and C3) used a 500-msec ISI and the tone control, and Version 4 (A4, B4, and C4) used a 2,000-msec ISI and the unrelated word control. In Version 5 (A5, B5, and C5), no primes were presented before the targets; Version 5 thus provided baseline measures of unprimed target responses.

The design was the same for all three types of phonological overlap. In each case, four priming conditions were tested, as defined by the relationship between primes and targets and by the instructions given to the participants. As is shown with examples in Table 1, phonological relatedness and participant expectations were manipulated factorially. In the ER condition, the target had a phonological form that both matched the expectations of the participant (given the prime) and was phonologically related to the prime, according to the type of overlap that was investigated in a given subexperiment (e.g., in the rhyme overlap case, honk-vonk, "base-spark"). Thus, for example, in Subexperiment A, given the prime honk, the target vonk was expected, because the participant had been led to expect a word rhyming with $/$ $n \mathrm{k} /$, given the prime honk, and vonk was related because it does indeed rhyme with honk. In the EU condition, the target was again expected, given the prime, but was phonologically unrelated to that prime (e.g., nest-galm, "nest-boom"). In this condition, given the prime nest, the participant had been led to expect a word rhyming with /alm/, such as galm, but these two words have no sounds in common. In the UR condition, the target was unexpected but related (e.g., nest-pest, "nest-plague"). Given the prime nest, the target pest does not rhyme with $/ \mathrm{alm} /$, as would be expected, but rather the prime and the target were related phonologically (e.g., 
nest and pest rhyme). Finally, in the UU condition, the target was both unexpected, given the prime, and phonologically unrelated to that prime (e.g., honk-mest, "base-manure"), since, given the prime honk, the target mest does not end with /onk/, as would be expected, and has no sounds in common with honk.

Note that these four conditions required three instantiations of the appropriate kind of phonological overlap in the targets. Thus, in the example above, the conditions required target words ending with the rimes $/ \mathrm{onk} /, / \mathrm{alm} /$, and $/ \varepsilon s t /$. It was impossible to find sufficient words within any subexperiment for the same set of three instantiations of phonological overlap to be used throughout that experiment. As will be described in more detail below, different sets of materials were therefore constructed, with each set containing the same four priming conditions. Thus, for example, the set with the rimes /onk/, $/ \mathrm{alm} /$, and /est/ was one of six different sets of items used in the rhyme overlap subexperiment.

Each such set of experimental items, together with control, filler, and practice items (see below) formed a block of trials. Each block involved only three different primes. One prime normally cued phonologically related word targets (as specified in the instructions for that block, and as occurred in practice, filler, and ER experimental trials; e.g., honk) but was also followed by phonologically unrelated nonword targets (in both the practice trials and the main part of the block) and was occasionally paired with an unexpected, unrelated word target (i.e., in UU trials). The second prime normally cued phonologically unrelated word targets (again as indicated in the instructions, and as occurred in practice, filler, and EU experimental trials; e.g., nest) and was also followed by unrelated nonwords but was sometimes followed by an unexpected, related word target (i.e., in UR trials).

The third prime was used in the control experimental trials and was also followed by nonword targets. In contrast to the other two primes, the control prime was the same in all blocks: a tone in Versions 1 and 3 of each subexperiment, and in Versions 2 and 4, a word that was unrelated to all the target words that it preceded in that subexperiment. The control trials consisted of the control prime used in that version of the experiment, followed by one of three types of control targets. These targets matched the three specific instantiations of phonological overlap in a given block. Thus, in the control-expected-related (XER) condition, targets had the same phonological structure as was expected in the ER condition (for the above example set, words that rhymed with /onk/). Targets in the control-expected-unrelated (XEU) condition had the same phonological structure as was expected in the EU condition (e.g., words rhyming with $/ \mathrm{alm} /$ ). Targets in the control-unexpected (XU) condition had the same phonological structure as occurred (unexpectedly) in the UR and UU conditions (e.g., words rhyming with/est/). These control conditions thus provided measures of performance on targets for which the prime provided no phonological expectancies. In Versions 1-4 of each subexperiment, these measures were collected within participants (but between items). In Version 5, baseline performance was also measured with new participants (but within items) on targets that were presented without any primes.

Before each block, the participants had to be instructed about which specific kinds of targets they ought to expect in that block, given the specific primes used in that block. They then received practice trials, which gave them the opportunity to learn those expectations (there were no unexpected trials during the practice sessions), followed by the main part of that block. After a given block, new instructions and practice were provided for the following block. In addition, each participant received an extra practice block at the beginning of the experiment, which involved yet another set of three instantiations of the appropriate kind of phonological overlap in the targets and specific instructions for those materials. This initial practice block contained no unexpected targets and provided the participants with initial training in learning to expect particular phonological patterns in targets, given primes with particular phonological patterns.
The expectancy instructions in any given block informed the participants that, after a given prime, a particular phonological structure in the following target would be predictive of the lexical status of that target. Specifically, the instructions took the following form: If you hear X, then you can expect that if the following item is a word, it will have a particular structure $Y$ (i.e., begins or ends with a given sound or sounds). The practice trials in that block then reinforced those expectancies: If a target was a word, it always had the expected phonological structure, given the preceding prime; if a target was a nonword, it did not have the structure that was expected after that prime, nor did it have any actual phonological overlap with that prime. Note, however, that words and nonwords were equally likely as targets after any given prime.

In summary, each subexperiment measured lexical decision performance on word targets that could have either an expected phonological form, given a particular prime, or an unexpected form and that could also be either phonologically related or unrelated to that prime. Any given participant had to deal with only one abstract type of phonological overlap (i.e., rhyme, one-phoneme, or threephoneme overlap), but given the constraints of the Dutch language, he or she had to learn different specific instantiations of those expectancies over the course of the experiment, in a number of different blocks. After an initial practice block, new sets of specific instructions were provided, and practice trials with those specific phonological expectancies were administered.

\section{Materials}

A: Rhyme overlap. Six blocks of items were constructed, consisting in each case of 24 Dutch words, 24 nonwords (which were phonologically legal in Dutch) that served as targets, and 2 additional words that served as primes. All the items were monosyllabic. The word targets had a mean frequency of occurrence of 29 per million words, according to the CELEX database (Baayen, Piepenbrock, \& van Rijn, 1993). All the items had a three-phoneme rime comprising a vowel and a consonant cluster and an onset that was either one or two consonants. That is, in terms of consonant-vowel (CV) structure, all of them had either a CVCC or a CCVCC form. Each item appeared in only one block.

In order to meet the constraints of the expectancy and relatedness conditions, the words in a given block all ended with one of three rimes. In the main part of a given block, there were six target words with each of these three rimes. One of these rimes was designated for use in the experimental ER trials (e.g., /onk/, to continue the earlier example; see Table 1). One of the prime words used specifically in that block therefore also had the same rime (e.g., honk). Of the six target words with this rime, two appeared in ER trials (e.g., honk-vonk), two in XER control trials, and two in filler trials. Of the six target words with the second rime (e.g., /alm/), two were used in EU trials (e.g., nest-galm), two in XEU control trials, and two in filler trials. Of the remaining targets with the third rime (e.g., /عst/), two were used in UR trials (e.g., nest-pest), two in UU trials (e.g., honk-mest), and two in XU control targets. The other prime used specifically in that block also had this rime (e.g., nest).

In the main part of each block, there were 18 nonword targets. Six were paired with one of the prime words that was specific to that block, 6 were paired with the other specific prime, and the remaining 6 were paired with control primes. Each block began with a set of practice trials, six with word targets and six with nonword targets. Three of the practice word targets were paired with the prime used in ER and UU trials (e.g., the prime honk) and, indeed, rhymed with that prime (i.e., these trials were equivalent to ER trials). The other three practice word targets were paired with the prime used in EU and UR trials (e.g., the prime nest) and had the same rime as the words used in EU trials (e.g., the rime /alm/; these trials were thus equivalent to EU trials).

In ER and UR trials, the primes and the targets shared three phonemes. Proportional overlap was also matched: On average, there was $70.0 \%$ overlap of ER targets with their primes and $72.5 \%$ over- 
lap of UR targets with their primes. Other than the phonological overlaps required for these experimental conditions, the primes and the targets shared no other segments. Thus, the nonword targets shared no phonemes with their matched primes, and the word targets also shared no phonemes with their primes, except for their rimes in related (ER and UR) trials. To achieve this, it was necessary to individually pair primes and targets in each block, and because of limitations in available materials, this constraint determined to some extent which sets of three rimes could be used within a block. Furthermore, the phonetic similarity of the three critical rimes within each block was kept as low as possible in order to make it easier for the participants to learn the expectancy mappings in each block. Individual selection of items for specific blocks and for specific prime-target pairings meant that it was impossible to rotate target items across experimental conditions. Any particular target word appeared in only one condition, paired with only one prime. These pairings are listed in the Appendix.

In addition to the stimuli for the six main blocks, a further set of 2 prime words, 18 target words, and 18 nonwords was selected for the initial practice block. Finally, 1 additional word was selected for use as the control prime that would be used in every block of trials in Versions 2 and 4 of the rhyme overlap subexperiment. This was the word $n u$, "now" (/ny/), which had no coda (i.e., had a CV structure different from all the targets') and did not overlap phonologically with any of the word targets (in fact, the vowel /y/ appeared only in three nonword targets in the entire subexperiment).

B: One-phoneme onset overlap. Material selection was very similar to that used in the rhyme overlap subexperiment. Blocks of materials again comprised 24 word targets, 24 nonword targets, and 2 word primes. All the items were again monosyllabic. They all had a single onset consonant (a CVC, CVCC, or CVCCC structure). The word targets had, according to the CELEX count, a mean frequency of 90 per million. Each target appeared only once. Within each block, the materials were assigned to conditions on the basis of sets of three consonants (as opposed to the sets of three rimes used in the rhyme overlap subexperiment). Thus, for example, one block involved the consonants $/ \mathrm{z} /, / \mathrm{v} /$ and $/ \mathrm{p} /$ (see Table 1 ). In this block, there were a prime beginning with /z/ (zeep, "soap"), 6 target words beginning with $/ z /$, including two for use in ER trials (e.g., zoon, "son"), and 3 practice target words beginning with $/ \mathrm{z} /$. There were also a prime beginning with $/ v /$ (wieg, "cradle") and 6 targets with the same onset, including 2 for use in UR trials (e.g., worst, "sausage") and UU trials (e.g., wijs, "wise"). Finally, there were 6 targets beginning with $/ \mathrm{p} /$, including 2 for use in EU trials (e.g., poes, "cat"), and 3 practice targets beginning with $/ \mathrm{p} /$. The items were further divided across conditions (control and filler word trials, nonword trials, and practice trials) and were assigned to blocks, following exactly the same procedure as that in the rhyme overlap subexperiment. Critically, all phonological overlap between the primes and the targets was avoided, except for their onset consonants in related trials. On average, there was $30.0 \%$ segmental overlap of ER targets with their primes and $31.2 \%$ segmental overlap of UR targets with their primes.

In contrast to the rhyme overlap subexperiment, however, there were only five experimental blocks. These five blocks, plus the initial practice block, required 18 different consonants; this exhausted the set of possible singleton onset consonants in Dutch for which enough words could be found. The full set of materials is given in the Appendix. The prime used for the control trials in Versions 2 and 4 of this subexperiment was $o o i$, "ewe" (/orj/). This word was again chosen to be phonologically distinct from all the targets: It had no onset consonant and, thus, had a different CV structure from all the targets, and it overlapped with only one target in the entire subexperiment (i.e., the VC sequence /o: $\mathrm{j}$ / appeared in only one experimental target and, hence, did not follow the prime ooi).

C: Three-phoneme onset overlap. The final set of materials consisted of six experimental blocks (again each comprising 2 prime words, 24 target words, and 24 target nonwords) and an initial prac- tice block. All the items were again monosyllabic. They all began with a two-consonant onset cluster and ended with one, two, or three consonants (i.e., CCVC, CCVCC, and CCVCCC structures). The word targets had a mean frequency of 18 per million according to CELEX. All the targets appeared only once. The procedure of item selection, pairing of primes and targets, and assignment to conditions and blocks was the same as that in the other two subexperiments, except that, here, the phonological overlap that was manipulated was the first three phonemes (the CCV sequences) of the stimuli (see the Appendix). Each block involved three different onsets divided across the expectedness and relatedness conditions (e.g., as is shown in Table 1 , the set based on $/ \mathrm{kna} /, / \mathrm{tr} \mathrm{J} /$, and $/ \mathrm{sl} / \mathrm{I} /$ ). As in the other subexperiments, there was no phonological overlap between primes and targets, except on the ER and UR trials. Proportional segmental overlap was again matched across conditions: There was, on average, $70.0 \%$ overlap of ER targets with their primes and $68.8 \%$ overlap of UR targets with their primes. Note, therefore, that in terms of proportional, as well as absolute, overlap, these conditions were matched to those in the rhyme overlap subexperiment. The word used as the control prime in Versions 2 and 4 of the three-phoneme onset overlap subexperiment was hooi, "hay" (/ ho:j/). Once again, this was chosen to avoid phonological overlap with any targets in this subexperiment (the CV structure was distinct from all targets, and neither $/ \mathrm{h} /$ nor /o:j/ appeared in any target).

\section{Procedure}

A female native speaker of Dutch recorded all of the stimuli in a sound-damped recording booth onto Digital Audio Tape, sampling at $48 \mathrm{kHz}$ with 16-bit quantization. The stimuli were redigitized, sampling at $16 \mathrm{kHz}$, during transfer to a computer running Xwaves speech-editing software. Individual speech files for each prime and target were made using Xwaves, and these files were then transferred to the personal computer that was used for running any particular version of the experiment.

In addition to the speech materials, a $500-\mathrm{Hz}$ sinusoidal tone was made. This was used as the control prime in Versions 1 and 3 of each subexperiment. The tone was $600 \mathrm{msec}$ long, which corresponded to the average duration of the primes (rhyme overlap, $602 \mathrm{msec}$; one-phoneme onset overlap, $540 \mathrm{msec}$; three-phoneme onset overlap, $517 \mathrm{msec}$ ). The mean durations of the targets were as follows: rhyme overlap, $645 \mathrm{msec}$; one-phoneme onset overlap, $567 \mathrm{msec}$; and three-phoneme onset overlap, $600 \mathrm{msec}$.

Although different versions of the experiment were run in different rooms, the experimental setup was the same in each case: The participants sat in separate sound-damped booths and listened to the stimuli over Sennheiser headphones; the experiment was controlled by a personal computer running NESU software; and written instructions were given. ISI was varied across the different versions of the experiment $(50,500$, or 2,000 msec).

Each experimental session for Versions 1-4 of each subexperiment began with an initial set of instructions that explained that the listener's task was to make lexical decisions on the second word in two-word sequences, using response buttons labeled $j a$ (yes) and nee (no), and that the first word in the sequence could be used to make predictions about the second word. None of the items in the instruction sessions was used in subsequent experimental trials. The instructions specified that within the first block of trials, there were only three words that would appear as the first word in the sequence (or only two words and a tone in Versions 1 and 3). One such word contained phonological material that was the same as that in the words it predicted (i.e., as in ER trials); the second word did not (i.e., as in EU trials). Thus, for example, the instructions in the rhyme overlap subexperiment stated that if the listeners heard start, id., they could expect that if the following item was a real Dutch word, it would usually rhyme with start, but that if they heard dump, id., they could expect that if the next item was a word, it would usually rhyme with /ens/. In the latter case, the listeners were told not to expect words rhyming with dump; they were told to shift their at- 
tention and expect a different phonological form. Finally, they were told that the third word (e.g.. $n u$ in Versions 2 and 4 of the rhyme overlap subexperiment) or the tone (in Versions 1 and 3) could not be used to predict anything about the lexical status of the second item conditional on phonological structure. That is, they were told that, after this control prime, a word was equally likely to contain each of the three phonological structures specified for that block (e.g., /art/, /ump/and /ens/). Example trials were provided as part of the written instructions.

After these instructions, the listeners received the initial practice block of trials. The 18 word and nonword targets for that subexperiment were presented, with their preceding primes, in random order. Each of the three primes occurred equally often, half with word targets and half with nonword targets. Each word target was consistent, given its prime, with the expectancies set up in the instructions (e.g., in the rhyme subexperiment, all words following start did rhyme with start; and all words following dump rhymed in /ens/). All nonword targets were phonologically unrelated to their preceding primes.

After this initial block, the main experimental blocks were presented. Before each block, new instructions were provided that were modeled on the initial instructions but specified the specific phonological expectancies that were appropriate for the upcoming block. For example, if the block was in the rhyme subexperiment and corresponded to the examples listed in Table 1, the listeners were told to expect that if they heard honk, they should expect that if the following item was a real word, it would usually rhyme with honk, and that if they heard nest they should expect that if the next item was a word, it would usually rhyme with /alm/.

Each experimental block began with 12 practice trials, which served to provide the listener with the opportunity to learn the new phonological expectancies. No target item presented during practice was used in the experimental trials. There were 6 trials with each of the two primes specific to that block (e.g., honk and nest); half appeared with word targets, and half with nonword targets. All the words were again consistent with the expectancies set up in the immediately preceding set of instructions, and all the nonwords were phonologically unrelated to their primes. Each trial was presented twice, for a total of 24 practice trials, in a single fixed random order of presentation.

The main part of the block was split into two sections. First, there were 8 filler trials containing four word targets (two after each block-specific prime, and all four consistent with expectancies) and 4 nonword targets (one after each block-specific prime and two after the control primes). These 8 trials were presented in random order. Second, with no pause (i.e., this break was not detectable by the participants), 28 experimental trials were presented. Fourteen of these trials had word targets that, depending on the pairing with one of the three primes, formed either one of the four experimental priming conditions ( 2 trials each in the ER, EU, UR, and UU conditions) or one of the three control conditions ( 2 trials each of XER, XEU, and $\mathrm{XU})$. The other trials had nonword targets: five after each of the two block-specific primes and four after the control primes). Again, these 28 trials were presented in random order. Thus, in the main part of an experimental block as a whole (i.e., 36 trials, including the filler trials), word and nonword targets were equally likely, and each of the two block-specific primes occurred equally often. There were only four unexpected word targets per block, and these occurred relatively late in each block (i.e., after at least 8 filler trials).

Two orders of presentation of the blocks within each subexperiment were constructed (for the five blocks in the one-phoneme overlap subexperiment; for the six blocks in the other two subexperiments). The first order, in each subexperiment, was based on the constraint that successive blocks should have critical overlaps that were as distinct as possible. This was to make it easier for the participants to learn the new expectancy mappings and to minimize confusion over blocks about what the expectancies were. The second order of presentation in each subexperiment was the reverse of the first. Block order was a between-participants factor.
This procedure was the same for Versions 1-4 of each subexperiment (i.e., for each ISI and each type of control prime for each type of overlap). The procedure was simplified in Version 5 of each subexperiment, however. In this version of the experiment, no primes were presented. The targets were identical to those in the other versions and were presented in exactly the same orders as in the other versions (but without the primes). The instructions were also simplified, since the participants in this version did not have to learn any phonological expectancies: The participants were asked to make lexical decisions on each auditory stimulus.

\section{Participants}

A: Rhyme overlap. Sixty-six members of the Max Planck Institute participant pool were paid for their participation. They had no known hearing problems. At least 12 of them participated in each of the five versions of this subexperiment (14 in A1, 50-msec ISI with tone control prime; 13 in A2, 50-msec ISI with unrelated word control prime; 15 in A3, 500-msec ISI with tone control prime; 12 in A4, 2,000-msec ISI with unrelated word control prime; and 12 in A5, unprimed baseline).

B: One-phoneme onset overlap. Sixty further volunteers from the same population were paid for their participation. They had no known hearing problems. Twelve of them participated in each of the five versions of this subexperiment (B1, B2, B3, B4, and B5).

C: Three-phoneme onset overlap. A further 63 volunteers from the same population were paid for their participation. They had no known hearing problems. At least 12 of them participated in each of the five versions of this subexperiment (14 in C1, 12 in $\mathrm{C} 2,13$ in $\mathrm{C} 3$, 12 in $\mathrm{C} 4$, and 12 in $\mathrm{C} 5$ ).

\section{RESULTS}

\section{Preliminary Analyses}

The accuracy data from the four versions of each subexperiment that had primes (Versions 1-4) were examined first. In the three-phoneme onset overlap subexperiment, three word targets were labeled as nonwords on $100 \%$ of the trials in Versions $\mathrm{C} 1$ and $\mathrm{C} 3$ (and two of these three words had 100\% no responses in Versions C2 and C4). These three words were excluded from all subsequent analyses. Mean RTs and mean error rates for each of the 105 cells of the design were then computed. These values are listed in Tables 2 and 3.

Selection of baseline. The experiment included three different measurements of baseline performance against which performance in the four critical priming conditions could be compared. Two of these measures were within participants but between items. In addition to the experimental trials, the listeners in Versions 1-4 received control trials: The listeners in Versions 1 and 3 heard target words preceded by tone primes, and the listeners in Versions 2 and 4 heard target words preceded by prime words that were phonologically unrelated to the targets. The targets in these control conditions were, however, different words from those in the experimental conditions. The third baseline measure was between participants but within items: The listeners in Version 5 heard the targets used in the other four versions, but they received no primes and no expectancy instructions.

Visual inspection of Tables 2 and 3 should make clear that the between-items control conditions used in Versions 1-4 (XER, XEU, and XU) cannot be used as baseline measures. If these conditions had provided stable 
Table 2

Mean Reaction Times (From Item Onset, in Milliseconds) in Each of the Four Experimental Conditions and Each of the Three Control Conditions for Each Type of Phonological Overlap, by Interstimulus Interval (ISI) and Type of Control Prime, With Example Stimuli for Each Condition for Each Type of Overlap

\begin{tabular}{|c|c|c|c|c|c|c|c|c|c|}
\hline \multirow[b]{2}{*}{ Overlap } & \multirow[b]{2}{*}{ ISI } & \multirow[b]{2}{*}{ Baseline } & \multicolumn{4}{|c|}{ Experimental Condition } & \multicolumn{3}{|c|}{ Control Condition } \\
\hline & & & ER & $\mathrm{EU}$ & UR & UU & XER & XEU & $\mathrm{XU}$ \\
\hline A. Rhyme & & & honk-vonk & nest-galm & nest-pest & honk-mest & X-stonk & $X$-walm & $X$-rest \\
\hline $\mathrm{A} 1$ & 50 & tone & 694 & 790 & 726 & 871 & 894 & 880 & 884 \\
\hline A2 & 50 & word & 700 & 804 & 736 & 838 & 886 & 869 & 866 \\
\hline A3 & 500 & tone & 765 & 858 & 799 & 898 & 947 & 937 & 951 \\
\hline A4 & 2,000 & word & 715 & 807 & 806 & 883 & 914 & 871 & 869 \\
\hline A5 & - & - & 783 & 835 & 801 & 876 & 942 & 877 & 885 \\
\hline B. One onset & & & zeep-zoon & wieg-poes & wieg-worst & zeep-wijs & $X-z o n$ & $X-p i t$ & $X$-wals \\
\hline B1 & 50 & tone & 751 & 676 & 829 & 798 & 782 & 749 & 807 \\
\hline $\mathrm{B} 2$ & 50 & word & 630 & 623 & 752 & 763 & 718 & 662 & 753 \\
\hline B3 & 500 & tone & 710 & 655 & 812 & 859 & 781 & 742 & 811 \\
\hline B4 & 2,000 & word & 741 & 709 & 885 & 915 & 790 & 795 & 852 \\
\hline B5 & - & - & 863 & 774 & 856 & 900 & 861 & 793 & 881 \\
\hline C. Three onset & & & $k n a k-k n a p$ & trog-slim & trog-trom & knak-tros & $X$-knarst & $X$-slip & $X$-trof \\
\hline $\mathrm{C} 1$ & 50 & tone & 866 & 851 & 848 & 939 & 1,008 & 956 & 954 \\
\hline $\mathrm{C} 2$ & 50 & word & 794 & 788 & 800 & 856 & 851 & 861 & 875 \\
\hline $\mathrm{C} 3$ & 500 & tone & 844 & 791 & 836 & 938 & 952 & 907 & 944 \\
\hline $\mathrm{C} 4$ & 2,000 & word & 862 & 822 & 861 & 904 & 916 & 900 & 921 \\
\hline C5 & - & - & 851 & 816 & 811 & 813 & 841 & 866 & 837 \\
\hline
\end{tabular}

Note-ER, expected related; EU, expected unrelated; UR, unexpected related; UU, unexpected unrelated; XER, control expected related; $\mathrm{XEU}$, control expected unrelated; $\mathrm{XU}$, control unexpected.

measures of auditory lexical decision when uninfluenced either by the phonological relatedness of the prime or by an expectancy based on that prime, there would have been few or no differences among the three control conditions. There were, however, large differences in both speed and accuracy among these conditions. Pairwise $t$ tests by both participants $\left(t_{1}\right)$ and items $\left(t_{2}\right)$ were carried out comparing
RTs in the XER, XEU, and XU conditions in Versions 1-4 of each subexperiment. Four of the RT differences between these conditions were significant by both participants and items: B1, XEU versus XU [mean difference, 58 msec; $\left.t_{1}(11)=2.57, p<.05 ; t_{2}(18)=2.33, p<.05\right]$; $\mathrm{B} 2$, XEU versus XU [mean difference, $91 \mathrm{msec} ; t_{1}(11)=$ $\left.5.25, p<.001 ; t_{2}(18)=3.08, p<.005\right]$; $\mathrm{B} 4, \mathrm{XER}$ versus

Table 3

Mean Error Rates (Proportions of Incorrect Responses) in Each of the Four Experimental Conditions and Each of the Three Control Conditions for Each Type of Phonological Overlap, by Interstimulus Interval (ISI) and Type of Control Prime, With Example Stimuli for Each Condition for Each Type of Overlap

\begin{tabular}{|c|c|c|c|c|c|c|c|c|c|}
\hline \multirow[b]{2}{*}{ Overlap } & \multirow[b]{2}{*}{ ISI } & \multirow[b]{2}{*}{ Baseline } & \multicolumn{4}{|c|}{ Experimental Condition } & \multicolumn{3}{|c|}{ Control Condition } \\
\hline & & & ER & EU & UR & UU & XER & XEU & $\mathrm{XU}$ \\
\hline A. Rhyme & & & honk-vonk & nest-galm & nest-pest & honk-mest & X-stonk & X-walm & $X$-rest \\
\hline A1 & 50 & tone & .036 & .065 & .041 & .155 & .131 & .202 & .244 \\
\hline A2 & 50 & word & .026 & .128 & .071 & .250 & .199 & .224 & .308 \\
\hline A3 & 500 & tone & .028 & .078 & .050 & .128 & .189 & .228 & .261 \\
\hline A4 & 2,000 & word & .000 & .069 & .056 & .236 & .139 & .167 & .271 \\
\hline A5 & - & - & .028 & .097 & .069 & .083 & .188 & .167 & .333 \\
\hline B. One onset & & & zeep-zoon & wieg-poes & wieg-worst & zeep-wijs & $X$-zon & $X-p i t$ & $X$-wals \\
\hline B1 & 50 & tone & .050 & .017 & .150 & .217 & .042 & .025 & .042 \\
\hline B2 & 50 & word & .058 & .033 & .233 & .275 & .067 & .025 & .100 \\
\hline B3 & 500 & tone & .058 & .025 & .283 & .242 & .075 & .025 & .100 \\
\hline B4 & 2,000 & word & .042 & .042 & .258 & .175 & .058 & .058 & .042 \\
\hline B5 & - & - & .083 & .033 & .150 & .075 & .067 & .017 & .017 \\
\hline C. Three onset & & & knak-knap & trog-slim & trog-trom & knak-tros & $X$-knarst & $X-$ slip & $X$-trof \\
\hline $\mathrm{C} 1$ & 50 & tone & .077 & .059 & .189 & .226 & .273 & .161 & .156 \\
\hline $\mathrm{C} 2$ & 50 & word & .104 & .069 & .303 & .306 & .313 & .174 & .220 \\
\hline C3 & 500 & tone & .058 & .071 & .245 & .256 & .336 & .250 & .266 \\
\hline $\mathrm{C} 4$ & 2,000 & word & .139 & .063 & .273 & .319 & .306 & .201 & .220 \\
\hline C5 & - & - & .161 & .078 & .236 & .139 & .283 & .156 & .176 \\
\hline
\end{tabular}

Note-ER, expected related; EU, expected unrelated; UR, unexpected related; UU, unexpected unrelated; XER, control expected related; XEU, control expected unrelated; XU, control unexpected. 
$\mathrm{XU}$ [mean difference, $62 \mathrm{msec} ; t_{1}(11)=3.91, p<.005$; $\left.t_{2}(18)=2.31, p<.05\right]$ and XEU versus XU [mean difference, $57 \mathrm{msec} ; t_{1}(11)=3.05, p<.05 ; t_{2}(18)=2.23 p<$ $.05]$. A further 9 of the 36 RT differences (spread across all three overlap subexperiments) were significant either by participants only or by items only. In analogous analyses of the error data, 10 of the differences were significant either by participants only or by items only (again, there were some significant differences within each of the three overlap subexperiments).

These differences probably reflect between-word differences in frequency and/or familiarity. Given the existence of these differences in the control conditions, any differences between responses to the control items and those to items in the experimental conditions are difficult, if not impossible, to interpret. It is also highly likely, however, given these results, that some of the differences among the experimental conditions were also due to between-items differences, rather than to the experimental manipulations. Version 5 of each subexperiment provided measures of unprimed lexical decisions on each of the targets. As is shown in Tables 2 and 3, there were indeed large differences in the speed and accuracy of responses to the targets in the experimental conditions even when no primes were presented. The data from Version 5 of each subexperiment were therefore used as the baseline against which performance in the other four versions was compared.

Data preparation. The unprimed data were used in two ways to prepare the primed data in the four experimental conditions. The control data within Versions 1-4 of each subexperiment (i.e., the XER, XEU, and XU data) were not considered further. First, words were excluded from all further analysis if one quarter or more of the listeners who heard those words in Version 5 judged them to be nonwords. Five words in the rhyme overlap subexperiment (flink, slips, tips, mocht, and stomp) had unprimed error rates of $25 \%$ or higher and were thus excluded, leaving $12,9,11$, and 11 words in the ER, EU, UR, and UU conditions, respectively. Four words in the one-phoneme overlap subexperiment (teen, sof, cel, and sas) were excluded for the same reason (leaving 9, 10, 8, and 9 words in the ER, EU, UR, and UU conditions, respectively). Finally, eight words were excluded using this criterion in the three-phoneme overlap subexperiment (knar, kwam, tronk, grol, prof, prol, zweemt, and klonk; this left 10,12,8, and 10 words in the ER, EU, UR, and UU conditions, respectively).

Second, the latency and error data in Versions 1-4 for these remaining items were adjusted to take into account between-item variability. The primed RT for each item was subtracted from the unprimed grand mean RT for that item. This adjustment was made for each item within each participant in Versions 1-4, prior to by-participant analyses, and for each item in Versions 1-4, prior to by-item analyses. The same adjustments to the error rates in the primed versions were made using the item error rates from Version 5. Positive values of these adjusted measures reflect faster or more accurate responses in primed than in unprimed con- ditions; negative values reflect slower or less accurate responses in primed than in unprimed conditions.

Finally, performance in Versions 1 and 2 was compared within each subexperiment. The only difference between these two versions, both of which had an ISI of $50 \mathrm{msec}$, was in the control primes: In Version 1, the control prime was the $500-\mathrm{Hz}$ tone; in Version 2, it was one of the three unrelated words ( $n u, o o i$, or hooi, depending on the subexperiment). This comparison thus provides a measure of whether the presence of a tone on each control trial had an effect on performance in the experimental trials different from that of the repeated presentation of the same unrelated prime word on each control trial. ANOVAs with either participant $\left(F_{1}\right)$ or item $\left(F_{2}\right)$ as the repeated measure were carried out on the RT and error data for the experimental trials in each subexperiment. Expectancy and relatedness were within-participants and between-items factors; the factor control type (tone vs. word) was a between-participants and within-items factor. There was a main effect of control type in only one of the six analyses (that for errors in Subexperiment $\mathrm{A}$ ). The listeners were less accurate (by $7 \%$, on average) on the experimental targets with rhyme overlap when the control prime was a word than when the control prime was a tone $\left[F_{1}(1,25)=7.26, p<.05 ; F_{2}(1,39)=\right.$ $8.89, p<.005]$. In this same analysis, there was an interaction between control type and relatedness $\left[F_{1}(1,25)=\right.$ $\left.4.39, p<.05 ; F_{2}(1,39)=4.23, p<.05\right]$. This interaction reflected the fact that the relatedness effect was larger with word control primes than with tone control primes (by $8 \%$, on average). The control primes therefore appear to have influenced the size of the relatedness effect but not the direction of the effect. In none of these analyses did the control type factor significantly interact with expectancy, nor were any of the three-way interactions significant. There was, however, one other significant interaction of control type with relatedness [in the RT analysis of Subexperiment $\mathrm{B}$, one-phoneme onset overlap; $F_{1}(1,22)=9.77$, $\left.p<.005 ; F_{2}(1,32)=14.73, p<.001\right]$. This interaction is related to a speed-accuracy trade-off in the $50-\mathrm{msec}$ ISI data in Subexperiment B, which will be discussed below.

These analyses thus show that performance on the experimental trials did not vary systematically as a function of the type of control trials present within the same experiment. In subsequent analyses, the data from Versions 1 and 2 were, therefore, combined. For the main analyses, adjusted RTs and error rates for each of the three types of phonological overlap in each of the four experimental priming conditions were compared for three ISIs: $50 \mathrm{msec}$ (combining Versions 1 and 2), $500 \mathrm{msec}$ (Version 3), and 2,000 msec (Version 4). These data are shown in Table 4.

\section{A. Rhyme Overlap}

The adjusted RT and accuracy results in the rhyme overlap subexperiment were submitted to repeated measures ANOVAs. Expectancy and relatedness were within-participants and between-items factors; ISI was a between-participants and within-items factor. The mean 
Table 4

Adjusted Mean Reaction Times (RTs, in Milliseconds) and Adjusted Mean Percentage Error Rates in Each of the Four Experimental Conditions for Each Type of Phonological Overlap, by Interstimulus Interval (ISI), With Example Stimuli for Each Condition for Each Type of Overlap

\begin{tabular}{|c|c|c|c|c|c|c|}
\hline \multirow[b]{2}{*}{ Overlap } & \multirow[b]{2}{*}{ Measure } & \multirow[b]{2}{*}{ ISI } & \multicolumn{2}{|c|}{ Expected } & \multicolumn{2}{|c|}{ Unexpected } \\
\hline & & & Related & Unrelated & Related & Unrelated \\
\hline \multirow[t]{7}{*}{ A. Rhyme } & & & honk-vonk & nest-galm & nest-pest & honk-mest \\
\hline & RT & 50 & 87 & 38 & 65 & -6 \\
\hline & & 500 & 18 & 12 & 3 & -21 \\
\hline & & 2,000 & 68 & 33 & -11 & -16 \\
\hline & Error & 50 & 0 & -5 & 0 & -11 \\
\hline & & 500 & 0 & -2 & 0 & -4 \\
\hline & & 2,000 & 3 & -3 & 0 & -13 \\
\hline \multirow[t]{7}{*}{ B. One onset } & & & zeep-zoon & wieg-poes & wieg-worst & zeep-wijs \\
\hline & RT & 50 & 160 & 123 & 59 & 111 \\
\hline & & 500 & 141 & 121 & 33 & 46 \\
\hline & & 2,000 & 115 & 60 & -53 & -19 \\
\hline & Error & 50 & 2 & 1 & -7 & -17 \\
\hline & & 500 & 1 & 1 & -11 & -15 \\
\hline & & 2,000 & 4 & -1 & -11 & -11 \\
\hline \multirow[t]{7}{*}{ C. Three onsets } & & & knak-knap & trog-slim & trog-trom & knak-tros \\
\hline & RT & 50 & 27 & 6 & -6 & -75 \\
\hline & & 500 & 25 & 36 & 31 & -117 \\
\hline & & 2,000 & 5 & 16 & -53 & -108 \\
\hline & Error & 50 & -4 & -2 & -4 & -18 \\
\hline & & 500 & -2 & -3 & -4 & -17 \\
\hline & & 2,000 & -5 & -2 & -9 & -25 \\
\hline
\end{tabular}

adjusted latency and accuracy data in each of the four experimental conditions at each of the three ISIs are plotted in Figure 1.

In the overall analysis, there was a relatedness effect. Responses were faster and more accurate to targets that rhymed with their primes (e.g., honk-vonk and nest-pest) than to targets that did not rhyme with their primes (e.g., honk-mest and nest-galm). This difference, however, was not fully reliable in the latency analysis [RTs, $F_{1}(1,51)=$ $26.67, p<.001$, and $F_{2}(1,39)=3.05, p=.09$; errors, $F_{1}(1,51)=26.71, p<.001$, and $F_{2}(1,39)=8.86, p<$ $.01]$. In addition, responses to expected targets (e.g., vonk in honk-vonk and galm in nest-galm) were also faster than responses to unexpected targets (e.g., mest in honk-mest and pest in nest-pest), although this difference was not significant by items $\left[F_{1}(1,51)=16.86, p<.001\right.$; $\left.F_{2}(1,39)=3.14, p=.08\right]$. Responses to expected targets were also more accurate than responses to unexpected targets, but this difference was again not significant by items $\left[F_{1}(1,51)=8.80, p<.005 ; F_{2}(1,39)=2.36, p>\right.$ .1]. In the latency analysis, there was an effect of ISI that was significant only by items $\left[F_{1}(2,51)=1.28, p>.2\right.$; $\left.F_{2}(2,78)=14.48, p<.001\right]$. Although the interaction of expectancy and relatedness and the three-way interaction of these factors with ISI were not significant, there were marginal interactions of both expectancy and relatedness with ISI. The expectancy effect in RTs became stronger at longer ISIs $\left[F_{1}(2,51)=2.96, p=.06 ; F_{2}(2,78)=\right.$ $4.16, p<.05]$, whereas the relatedness effect in RTs became weaker at longer ISIs $\left[F_{1}(2,51)=3.08, p=.05\right.$; $\left.F_{2}(2,78)=2.73, p=.07\right]$. In the accuracy analysis, there was no significant effect of ISI, nor were any interactions involving ISI significant. The interaction of expectancy and relatedness, however, was significant by participants $\left[F_{1}(1,51)=6.77, p<.05 ; F_{2}(1,39)=1.47, p>.2\right]$.

Subanalyses for each ISI condition confirmed that both the expectancy and the relatedness effects varied with ISI. At the 50-msec ISI, the only reliable effect was that of relatedness. Responses to targets that rhymed with their primes were faster $\left[F_{1}(1,26)=57.22, p=.001 ; F_{2}(1,39)=7.70\right.$, $p<.01]$ and more accurate $\left[F_{1}(1,26)=15.41, p=.001\right.$; $\left.F_{2}(1,39)=8.35, p<.01\right]$ than responses to targets that did not rhyme with their primes. There were no significant effects at the 500-msec ISI: The relatedness effect was no longer detectable, and there was no expectancy effect either. At the 2,000-msec ISI, however, there was an expectancy effect. Responses were faster $\left[F_{1}(1,11)=\right.$ $\left.5.85, p<.05 ; F_{2}(1,39)=6.06, p<.05\right]$ and more accurate $\left[F_{1}(1,11)=11.13, p<.01 ; F_{2}(1,39)=4.48, p<\right.$ $.05]$ to expected than to unexpected targets. Although there was no relatedness effect in the latency analysis at the 2,000-msec ISI, responses to targets that rhymed with their primes were more accurate than responses to targets that were phonologically unrelated to their primes $\left[F_{1}(1,11)=19.04, p<.005 ; F_{2}(1,39)=9.13, p<.005\right]$. The interaction of relatedness and expectancy was not significant in either RTs or errors at any ISI.

In the rhyme overlap subexperiment, therefore, the results were as predicted. The listeners were faster and more accurate on targets that actually rhymed with their primes than on phonologically unrelated targets, but only at the shortest ISI. At longer ISIs, there were no significant relatedness effects, except in error rates when there was a 2 -sec delay. The processing benefit due to actual phono- 

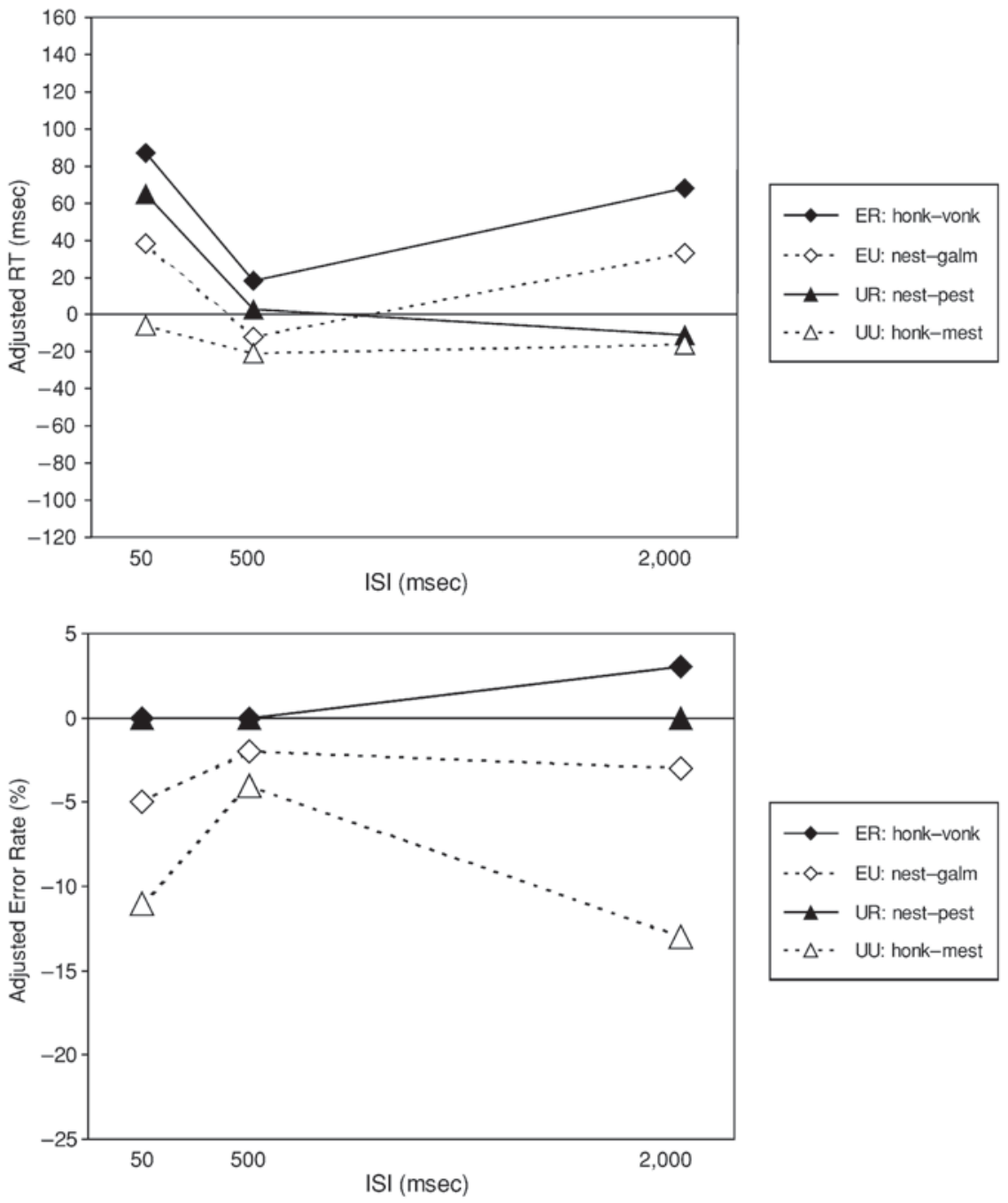

Figure 1. Rhyme overlap: adjusted reaction times (RTs, in milliseconds; upper panel) and adjusted error rates (lower panel). The data are plotted with example stimuli at three interstimulus intervals (ISIs; 50,500 , and 2,000 msec) for each of the four priming conditions: expected related (ER), expected unrelated (EU), unexpected related (UR), and unexpected unrelated (UU).

logical overlap between primes and targets therefore appears to decay over time. Furthermore, the listeners were able to learn rhyme-based expectancies, such that lexical decisions were biased in favor of expected targets. This expectancy bias was observed most clearly at longer ISIs: It was significant only when there was a 2 -sec delay between primes and targets. These results suggest that there is an automatic component of rhyme overlap phonological priming that influences lexical decision performance (particularly at short ISIs), despite any expectancies that the listener may have, and a strategic expectancy bias that builds up with increasing ISI.

\section{B. One-Phoneme Onset Overlap}

Parallel analyses were performed on the adjusted data in the one-phoneme onset overlap subexperiment. The mean results in each of the four experimental conditions at each of the three ISIs are plotted in Figure 2. Responses to expected targets (e.g., zoon in zeep-zoon and poes in wieg-poes) were faster than responses to unexpected targets [e.g., wijs in zeep-wijs and worst in wieg-worst; $\left.F_{1}(1,45)=54.62, p<.001 ; F_{2}(1,32)=17.60, p<.001\right]$. Responses to expected targets were also more accurate than responses to unexpected targets $\left[F_{1}(1,45)=31.07\right.$, $\left.p<.001 ; F_{2}(1,32)=20.97, p<.001\right]$.

In addition, there was a main effect of ISI, but only in the latency analysis: Responses tended to be faster at shorter ISIs $\left[F_{1}(2,45)=3.22, p<.05 ; F_{2}(2,64)=44.52\right.$, $p<.001]$. No other effects were significant by both participants and items in either the latency or the error analysis. The interaction of expectancy with ISI in RTs was significant only by items $\left[F_{1}(2,45)=2.50, p<.1\right.$; 

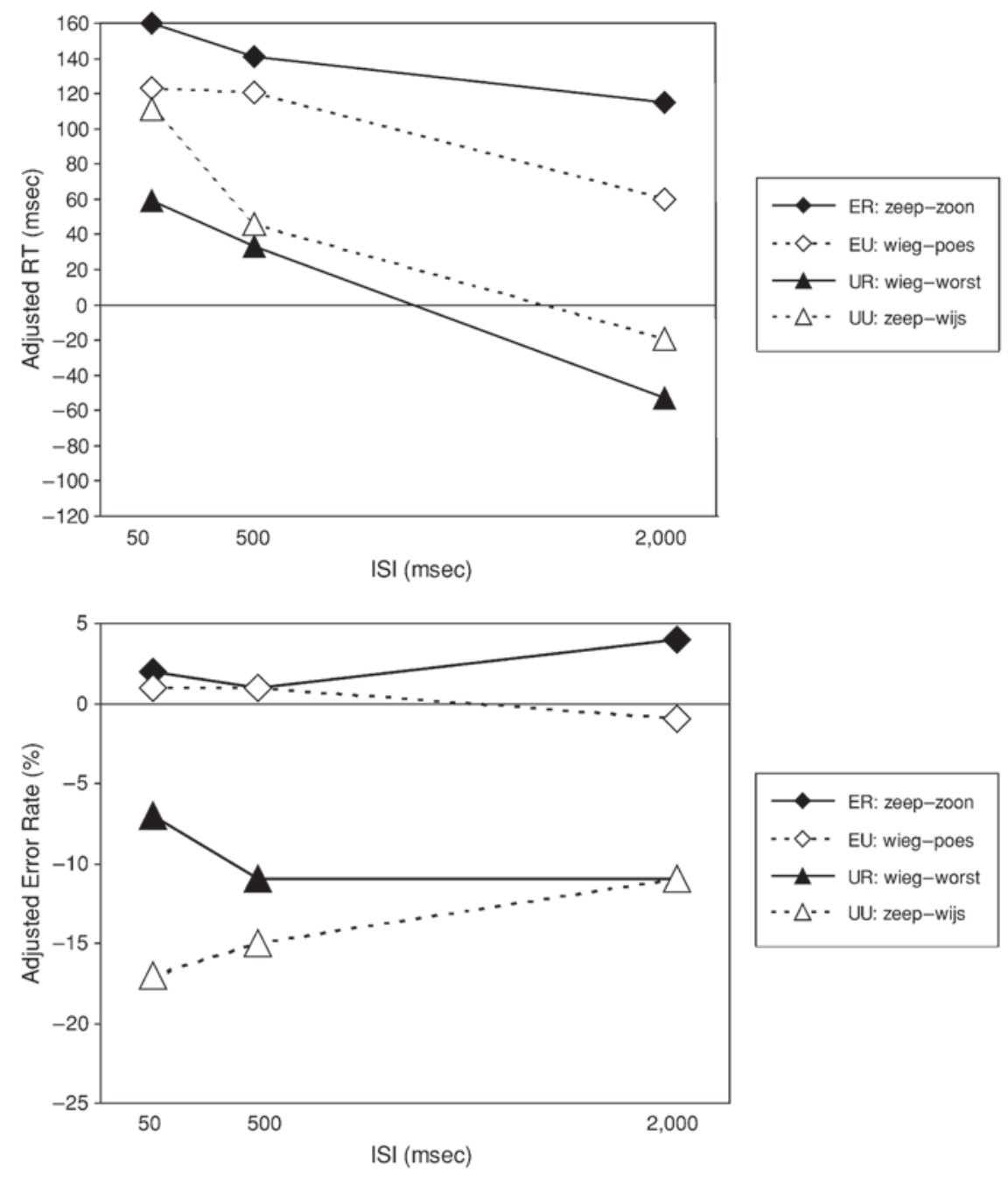

Figure 2. One-phoneme onset overlap: adjusted reaction times (RTs, in milliseconds; upper panel) and adjusted error rates (lower panel). The data are plotted with example stimuli at three interstimulus intervals (ISIs; 50, 500, and 2,000 msec) for each of the four priming conditions: expected related (ER), expected unrelated (EU), unexpected related (UR), and unexpected unrelated (UU).

$\left.F_{2}(2,64)=6.26, p<.005\right]$, with the effect of expectancy tending to be stronger at longer ISIs.

Subanalyses were again then performed for each ISI condition. The expectancy effect in latencies was significant by both participants and items at each ISI [ $50 \mathrm{msec}$, $F_{1}(1,23)=15.18, p<.001$, and $F_{2}(1,32)=7.18, p<$ $.05 ; 500 \mathrm{msec}, F_{1}(1,11)=9.73, p<.01$, and $F_{2}(1,32)=$ $15.92, p<.001 ; 2,000 \mathrm{msec}, F_{1}(1,11)=32.56, p<.001$, and $\left.F_{2}(1,32)=19.41, p<.001\right]$. Likewise, the expectancy effect in the accuracy data was also fully reliable at all three ISIs [50 msec, $F_{1}(1,23)=13.63, p<.005$, and $F_{2}(1,32)=13.32, p<.001 ; 500 \mathrm{msec}, F_{1}(1,11)=11.61$, $p<.01$, and $F_{2}(1,32)=10.77, p<.005 ; 2,000 \mathrm{msec}$, $F_{1}(1,11)=12.24, p<.01$, and $F_{2}(1,32)=19.10, p<$ $.001]$. At each ISI, therefore, responses were faster and more accurate to target words that matched the listeners' expectancies than to those that mismatched their expectan- cies. There was no significant relatedness effect in either speed or accuracy at any ISI, nor did the relatedness and expectancy effects interact significantly, with one exception: at 50-msec ISI, in the latency analysis $\left[F_{1}(1,23)=\right.$ $\left.27.35, p<.001 ; F_{2}(1,32)=4.59, p<.05\right]$. At this ISI, there was a large expectancy advantage for related targets (101 msec, on average) but only a very small advantage for unrelated targets (12 msec, on average). This interaction appears to reflect a speed-accuracy trade-off. Although the relatedness-expectancy interaction in the errors was not fully reliable $\left[F_{1}(1,23)=4.81, p<.05 ; F_{2}(1,32)=\right.$ $1.65, p>.2]$, the expectancy effect was stronger for unrelated targets (18\%, on average) than for related targets ( $9 \%$, on average). As is shown in Figure 2, this trade-off appears to be due primarily to responses in the UU condition (e.g., zeep-wijs), which, at $50 \mathrm{msec}$, were fast but inaccurate. Furthermore, this trade-off appeared only in 
Version 1 (50-msec ISI with tone control primes) and, thus, appears to also account for the interaction of control type and relatedness mentioned earlier in the comparison of Versions 1 and 2. The speed-accuracy trade-off also disappeared at longer ISIs.

The results for the one-phoneme overlap condition were, therefore, also consistent with our predictions. There was a robust effect of expectancy at all ISIs, with a tendency for this effect to become stronger at longer ISIs (the interaction of ISI with expectancy was not fully reliable). The listeners were able to learn to make use of phonological expectancies to bias their lexical decisions, both when the target words were phonologically related to the primes (e.g., zeep-zoon, where both begin with/z/) and when the targets were phonologically unrelated to the primes (e.g., faster and more accurate responses to poes, after the prime wieg, when listeners had been told to expect, after wieg, that if the target was a word, it would begin with a $/ \mathrm{p} /$ ).

These results contrast with those for rhyme overlap. In the one-phoneme onset overlap case, the phonological information involved in the expectancies appeared at the beginnings of the stimuli and, thus, could be used both rapidly and predictively (i.e., to anticipate the phonological form of the onsets of the targets). It could therefore be used in the development of an expectancy strategy even at 50-msec ISI. In contrast, rhyme overlap appears at the ends of the stimuli and, thus, cannot be used as rapidly or as predictively as onset overlap.

Furthermore, there were no reliable effects of phonological relatedness, given overlap of one onset phoneme. Responses were not faster or more accurate to targets that shared their first consonant with their primes than to targets that were phonologically unrelated to their primes. These results again contrast with those for rhyme overlap, where a relatedness effect was found at short ISIs. It appears that a single consonant is not sufficient phonological overlap for automatic facilitation of processing to be observed.

\section{Three-Phoneme Onset Overlap}

The adjusted data in each of the four experimental conditions in the three-phoneme onset overlap subexperiment were analyzed in the same way. The mean results at each of the three ISIs are plotted in Figure 3. Overall, responses to expected targets (e.g., knap in knak-knap and slim in trog-slim) were faster than responses to unexpected targets [e.g., tros in knak-tros and trom in trog-trom; $\left.F_{1}(1,48)=39.92, p<.001 ; F_{2}(1,36)=12.40, p<.005\right]$. Responses to expected targets were also more accurate than responses to unexpected targets $\left[F_{1}(1,48)=18.27\right.$, $\left.p<.001 ; F_{2}(1,36)=25.74, p<.001\right]$. There was also a relatedness effect in the latency analysis $\left[F_{1}(1,48)=\right.$ $\left.17.48, p<.001 ; F_{2}(1,36)=2.07, p>.1\right]$. Since this RT effect was significant only by participants, it appears that it is carried by some items, but not by all. In the error analysis, however, the relatedness effect was fully reliable $\left[F_{1}(1,48)=22.20, p<.001 ; F_{2}(1,36)=10.39, p<\right.$ $.005]$. Responses were more accurate for related targets that had the same first three phonemes as their primes (e.g., trom in trog-trom) than for unrelated targets (e.g., tros in knak-tros). There was also an interaction between expectancy and relatedness that was significant only by participants in the RT analysis $\left[F_{1}(1,48)=24.26, p<\right.$ $\left..001 ; F_{2}(1,36)=2.09, p>.1\right]$. The interaction between expectancy and relatedness was, however, fully reliable in the error analysis $\left[F_{1}(1,48)=26.04, p<.001\right.$; $\left.F_{2}(1,36)=14.15, p<.001\right]$. There was an expectancy effect in accuracies for unrelated targets (e.g., trog-slim [EU] vs. knak-tros [UU]), and there was a relatedness effect in accuracies for unexpected targets (e.g., trog-trom [UR] vs. knak-tros [UU]). As is shown in Figure 3, the expectancy $\times$ relatedness interaction in the error data was carried mainly by the poor performance on the UU trials (e.g., knak-tros).

Pairwise comparisons confirmed the pattern that is evident in the error rates in Figure 3-namely, that performance was poorer on the UU trials (e.g., knak-tros) than on the other types of trials. The only significant differences were those involving the UU condition: Error rates were lower on EU trials (e.g., trog-slim) than on UU trials $\left[F_{1}(1,48)=31.75, p<.001 ; F_{2}(1,20)=43.53, p<\right.$ $.001]$ and were lower on UR trials (e.g., trog-trom) than on UU trials $\left[F_{1}(1,48)=37.53, p<.001 ; F_{2}(1,16)=12.45\right.$, $p<.005]$.

In addition, there was an effect of ISI, but this effect was only marginally significant by items in the latency and error analyses [RTs, $F_{1}(2,48)<1$, and $F_{2}(2,72)=$ $3.04, p=.05$; errors, $F_{1}(2,48)<1$, and $F_{2}(2,72)=2.86$, $p=.06]$. No other effects were significant by both participants and items in either the latency or the error analysis.

Subanalyses for each ISI produced similar patterns of results. At the 50-msec ISI, in the latency analysis, the expectancy effect was fully reliable $\left[F_{1}(1,25)=17.52, p<\right.$ $\left..001 ; F_{2}(1,36)=5.76, p<.05\right]$, but the relatedness effect was significant only by participants $\left[F_{1}(1,25)=19.51\right.$, $\left.p<.001 ; F_{2}(1,36)=3.35, p=.08\right]$, and the interaction was also significant only by participants $\left[F_{1}(1,25)=\right.$ $\left.6.04, p<.05 ; F_{2}(1,36)<1\right]$. In the error analysis, however, this pattern was statistically fully robust. Responses were more accurate on expected than on unexpected targets $\left[F_{1}(1,25)=9.58, p<.005 ; F_{2}(1,36)=13.36, p<\right.$ $.001]$ and were more accurate on related than on unrelated targets $\left[F_{1}(1,25)=10.44, p<.005 ; F_{2}(1,36)=7.17, p<\right.$ $.05]$, and these two effects interacted $\left[F_{1}(1,25)=13.32\right.$, $\left.p<.005 ; F_{2}(1,36)=10.35, p<.005\right]$. As in the overall analysis, pairwise comparisons examining this interaction showed that error rates were lower on EU trials than on UU trials $\left[F_{1}(1,25)=17.18, p<.005 ; F_{2}(1,20)=23.08\right.$, $p<.001]$ and were lower on UR trials than on UU trials $\left[F_{1}(1,25)=19.25, p<.005 ; F_{2}(1,16)=10.13, p<.01\right]$. No other pairwise comparisons were significant.

At the 500-msec ISI, the expectancy effect in latencies was again fully reliable $\left[F_{1}(1,12)=9.36, p<.01\right.$; $\left.F_{2}(1,36)=15.19, p<.001\right]$, the relatedness effect was significant only by participants $\left[F_{1}(1,12)=8.94, p<\right.$ $\left..05 ; F_{2}(1,36)=1.93, p>.1\right]$, and the interaction was significant only by participants $\left[F_{1}(1,12)=16.87, p<.005\right.$; $\left.F_{2}(1,36)=3.30, p=.08\right]$. In the error analysis, responses 

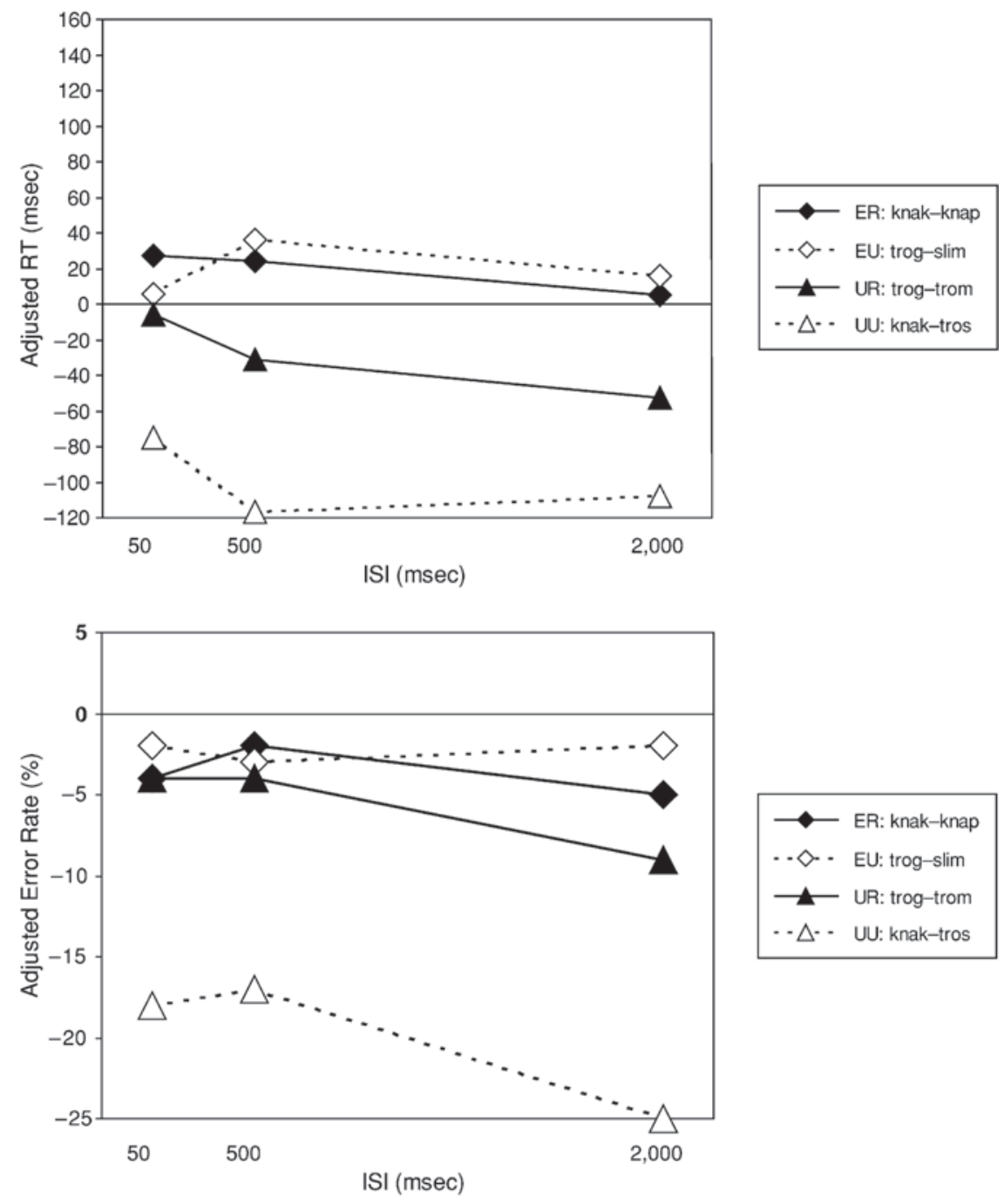

Figure 3. Three-phoneme onset overlap: adjusted reaction times (RTs, in milliseconds; upper panel) and adjusted error rates (lower panel). The data are plotted with example stimuli at three interstimulus intervals (ISIs; 50, 500, and $2,000 \mathrm{msec}$ ) for each of the four priming conditions: expected related (ER), expected unrelated (EU), unexpected related (UR), and unexpected unrelated (UU).

were once again more accurate for expected than for unexpected targets $\left[F_{1}(1,12)=7.31, p<.05 ; F_{2}(1,36)=7.11\right.$, $p<.05]$ and were also again more accurate for related than for unrelated targets $\left[F_{1}(1,12)=25.13, p<.001\right.$; $\left.F_{2}(1,36)=4.70, p<.05\right]$. The interaction of these two effects was, however, not significant by items $\left[F_{1}(1,12)=\right.$ $\left.5.81, p<.05 ; F_{2}(1,36)=3.46, p=.07\right]$. Pairwise comparisons showed that error rates were again lower on EU trials than on UU trials $\left[F_{1}(1,12)=11.03, p<.01\right.$; $\left.F_{2}(1,20)=10.00, p<.005\right]$ and on UR trials than on UU trials $\left[F_{1}(1,12)=19.69, p<.005 ; F_{2}(1,16)=5.04, p<\right.$ $.05]$. Neither of the other two pairwise comparisons was significant.

At the 2,000-msec ISI, the only significant effect in the latency analysis was that of expectancy: Expected targets were responded to more rapidly than unexpected targets $\left[F_{1}(1,11)=13.04, p<.005 ; F_{2}(1,36)=9.79, p<.005\right]$. In errors, neither the expectancy $\left[F_{1}(1,11)=4.22, p=\right.$ $\left..06 ; F_{2}(1,36)=21.72, p<.001\right]$ nor the relatedness $\left[F_{1}(1,11)=4.11, p=.07 ; F_{2}(1,36)=4.72, p<.05\right]$ effect was fully reliable, but the interaction was $\left[F_{1}(1,11)=\right.$ $\left.10.84, p<.01 ; F_{2}(1,36)=10.02, p<.005\right]$. The only significant pairwise comparisons were, once again, those involving the UU trials: There were fewer errors on EU trials than on UU trials $\left[F_{1}(1,11)=7.91, p<.05\right.$; $\left.F_{2}(1,20)=29.20, p<.001\right]$, and there were fewer errors on UR trials than on UU trials $\left[F_{1}(1,11)=9.07, p<.05\right.$; $\left.F_{2}(1,16)=9.31, p<.01\right]$.

In contrast to the results for both of the other types of overlap, those for three-phoneme onset overlap therefore 
appear to reflect both expectancy and relatedness effects and their interaction, at all three ISIs. There were main effects of both relatedness (although this was fully reliable only by participants in the latency analysis) and expectancy. In the rhyme overlap subexperiment, relatedness effects were strongest at the shortest ISI, and expectancy effects were strongest at the longest ISI. Here, however, the relatedness and expectancy effects tended to overlap more in time. Nevertheless, the relatedness effect was stronger at shorter ISIs (as in the rhyme subexperiment), and the expectancy effect was present at all ISIs and tended to build up over time (as in the one-phoneme onset overlap subexperiment). The results for three-phoneme onset overlap are thus consistent with the earlier findings and suggest that both automatic and controlled processes were operating under these conditions.

The evidence for the role of automatic processes in three-phoneme onset priming was that the listeners were faster and more accurate on targets that overlapped phonologically with their primes (e.g., knak-knap) than on phonologically unrelated targets (e.g., knak-tros). This processing benefit, due to actual phonological overlap between primes and targets, decayed over time for both three-phoneme onset overlap and rhyme overlap (recall that the rhyme manipulations also involved threephoneme overlap, but at word offset). Three-phoneme overlap therefore appears to be as effective in producing facilitation when it appears at word onset as when it appears at word offset. The facilitation due to repeated activation of the same prelexical representations by prime and target appears to decay over time. In the introduction, we suggested that there may be automatic inhibitory effects with three-phoneme onset overlap (due to competition between candidate words). There was, however, no trace of such effects. It would appear, therefore, that at least under the conditions tested here, facilitation due to segmental overlap in onset position seems to dominate any inhibition due to lexical competition. We will return to this issue in the Discussion section.

The evidence for the role of controlled processes in the three-phoneme onset overlap condition was the robust effect of expectancy at all ISIs. This effect became stronger at longer ISIs - a pattern identical to that found with onephoneme onset overlap. The listeners were thus able to make use of phonological expectancies to bias their lexical decisions. As in the one-phoneme onset overlap case, the phonological information involved in the expectancies appeared at the beginning of the stimuli and, thus, could be used by the listeners, even at the shortest ISIs, to anticipate the phonological form of the target onsets.

Unlike the results for rhyme or one-phoneme onset overlap, the three-phoneme overlap condition exhibits clear interaction effects at all ISIs. The interaction of the relatedness and the expectancy effects suggests that the automatic and the controlled processes underlying these effects are not independent. Note that this interaction was significant only by participants in the latency data but was fully reliable in error rates. Two aspects of this interaction are noteworthy. First, it appears that the application of an expectancy strategy overrode any benefit that might have been due to actual phonological overlap, but only when the expectancy was confirmed. Thus, responses to ER targets (e.g., knak-knap) were no faster or more accurate than those to EU targets (e.g., trog-slim). A word beginning kna, for example, appears to have been no better a match to the expectancy triggered by knak than a word beginning sli was a match for the expectancy triggered by trog. In contrast, however, when the expectancy was not confirmed, performance was very poor (in UU trials, such as knak-tros), unless there was actual phonological overlap available (in UR trials, such as trog-trom). The automatic facilitation due to phonological overlap between the prime and the target in these trials appeared most clearly when there was no contributing effect of expectation. Second, it appears that the processing benefit due to actual phonological overlap dominated any effect due to expectancy. Thus, responses to ER targets were not faster or more accurate that those to UR targets. A word beginning with kna, for example, appears to have been just as good a match to knak as an unexpected, yet phonologically related, prime-target pair (e.g., trog-trom). However, when the prime and the target were not related, expectancy effects predominated, and performance for EU targets (e.g., trog-slim) was better compared with that for UU targets (e.g., knak-tros). Thus, in three-phoneme onset overlap, the interaction of expectancy and relatedness at all three ISIs appears as a phonological relatedness effect for unexpected prime-target pairs and as a strategic expectancy bias for unrelated prime-target pairs.

It is important to note that the bias in this subexperiment appears to act primarily to disfavor unexpected or unrelated targets, rather than to favor expected or related targets. As is shown in Figure 3, the functions for the expected or related trials are close to the zero line (both in RTs and errors), whereas functions for the UU trials are well below zero. That is, performance for expected or related targets is close to that for these targets when unprimed, whereas that for the UU targets is considerably worse than when they are unprimed. This pattern contrasts with the expectancy effects and relatedness effects observed for the other two types of phonological overlap. For the one-phoneme onset overlap case, the expectancy bias appears to speed responses to expected targets more than it slows responses to unexpected targets. Similarly, for rhyme overlap, relatedness appears to speed responses to related targets more than it slows responses to unrelated targets. These differences may reflect the difficulty of processing expectancies and relatedness relations on the basis of different types of phonological overlap. Sequences of three onset phonemes are longer and more complex than single onset phonemes. Furthermore, threephoneme onset sequences do not have the familiarity and salience of rhyming sequences, nor do they correspond to a single subsyllabic structure. That is, even though our rhyme overlap manipulations also involved three phonemes, listeners are much more familiar with manipulat- 
ing rhymes than alliterations, and the rhyming sequences corresponded to the rimes of the target words (the nucleus plus the coda of the syllables), whereas the three-phoneme onset sequences consisted of the onset plus the nucleus of the syllables (i.e., not to a single subsyllabic structure).

The demanding task of processing expectancies and relatedness relations on the basis of three onset phonemes may thus have acted primarily to impair performance on unexpected and unrelated targets. The listeners had the tendency to make no responses to UU targets, such as tros after knak (on about one in five such trials), and to be very slow on correct yes responses to these targets. Detection of a mismatch in expectations and phonological overlap would lead to this pattern of performance. In contrast, any phonological or expectancy match appears to have been beneficial. Specifically, performance on UR trials (e.g., trog-trom) was quite good. It is possible that automatic facilitation arising from repeated activation of prelexical representations corresponding to the / $\mathrm{tr} /$ sequence may have speeded recognition of trom and, thus, counteracted the inhibitory effects due to an expectancy mismatch. EU trials (e.g., trog-slim) also show better performance. It is possible that a response bias based on expectancy could have speeded recognition of slim, despite the lack of actual phonological overlap. On this view, then, the reason why performance on ER trials (e.g., knak-knap) was no better than that on EU trials (e.g., trog-slim) is that once the match with expectancies was detected, a yes response could be initiated, regardless of phonological overlap. Because there were never any partial overlap trials (e.g., a target word beginning with $/ \mathrm{knI} /$ after knak), detection of an expectancy match could, in principle, occur relatively early, and a yes response could be initiated immediately. In summary, then, the interaction of expectancy and relatedness effects with three-phoneme onset overlap appears to reflect both automatic and controlled processes. ${ }^{1}$

\section{DISCUSSION}

Our application of the Neely (1977) paradigm to phonological priming was successful. We were able to cleave automatic processes from strategic biases. In the case of rhyme overlap, we found evidence of automatic facilitatory processes, particularly at short ISIs $(50 \mathrm{msec})$, and evidence of expectancy-based strategies, particularly at long ISIs $(2,000 \mathrm{msec})$. This is the pattern that we predicted. We have suggested that the facilitatory effect of actual phonological overlap (the relatedness effect) is due to the repeated activation of the same prelexical representations by the prime and the target. As was observed, this effect should become weaker over time, as the activation of prelexical representations caused by the prime returns to resting levels. We also predicted that the expectancy effect would tend to be largest at the longest ISI, for a number of reasons. More time between the prime and the target gives participants more time to apply an expectancy strategy. Furthermore, since the expectancy concerned word-final information, the listeners had to wait longer for the matching information before they could deploy the strategy. Rhyme overlap thus shows fast-acting automatic facilitatory effects that fade rapidly over time, as well as slower strategic effects that appear only at the longest ISIs.

There was neither a relatedness effect nor an expectancy effect in the rhyme overlap subexperiment with a $500-\mathrm{msec}$ ISI. One possible explanation for this finding is simply that at $500 \mathrm{msec}$, the automatic mechanism responsible for the relatedness effect observed at a $50-\mathrm{msec}$ ISI has a short enough time course for there to be no significant facilitation and that there was not enough time for the listeners to apply the expectancy strategy seen at the 2,000-msec ISI. The automatic facilitation can be observed at the shortest, 50 -msec ISI, but the processing benefit due to actual overlap decays rapidly. Consequently, at the 500-msec ISI, the facilitation due to repeated activation of the same prelexical representation of the prime and the target is not evident anymore. In a complementary fashion, the slower-acting expectancy effect that can be observed at the longest ISIs does not have enough time at a 500 -msec ISI to be fully engaged. For rhyme overlap, the phonological information involved in the expectancies appeared at the end of the stimuli and, therefore, could not be used as rapidly to anticipate subsequent target items. Rhyme overlap thus shows neither automatic nor strategic effects at the intermediate ISI condition.

An alternate explanation for the lack of either a relatedness or an expectancy effect with rhyme overlap at the 500 -msec ISI is that the listeners may have been discouraged from applying an expectancy strategy. They may have noticed the UR trials (e.g., nest-pest), because of the salience of rhyme overlap (Slowiaczek et al., 2000), and thus have chosen to abandon any expectancy bias. The UR trials could, thus, have acted in a way similar to that of the foils that Norris et al. (2002) showed could act to suppress rhyme-based response biases. If this account were correct, one might predict that there would be evidence of an expectancy bias early in the experiment (i.e., before the participants noticed the UR trials). An analysis comparing performance over experimental blocks failed to find support for this prediction. Nevertheless, it is possible that the participants detected the very first UR trial (cf. Pitt \& Shoaf, 2002). On this account, the reason why the participants did use an expectancy strategy at the 2,000-msec ISI is that they had enough time not only to detect the UR trials, but also to choose to ignore them. That is, the 2,000-msec ISI gave the participants enough time to apply the expectancy biases that they had learned from the instructions and during the practice trials in a rigorous fashion, without being misled by the UR "foils." It is, then, possible that the patterns at the $500-\mathrm{msec}$ ISI were due, in part, to there being little time to apply a strategy and, in part, to the disruptive effect of the UR trials. Whatever the explanation for the $500-\mathrm{msec}$ data, however, it is clear that rhyme overlap can produce automatic facilitation at short ISIs and can be used in expectancy strategies at long ISIs.

We are, therefore, in a position to answer one of the questions posed in the introduction. Norris et al. (2002) 
observed reliable facilitation at short ISIs in auditory lexical decision with rhyme overlap materials, but this facilitation was much reduced when foils were included in the experiment. Why was this the case, if rhyme overlap facilitation is due to automatic prelexical processes? We suggested earlier that this may have been because the presence of foils could induce a checking strategy, which masked the automatic facilitation. In the present experiment, we did detect automatic effects in the auditory lexical decision task at short ISIs. It therefore appears likely that such automatic effects in Norris et al.'s study were indeed masked by a checking strategy. Thus, although it is clear that lexical decision performance can be influenced by strategic processes, automatic facilitation can be detected by the lexical decision task, at least under some circumstances. The facilitation observed in standard versions of the task and, indeed, in other tasks, such as shadowing (Slowiaczek et al., 2000), is probably due, in part, to automatic prelexical processes and, in part, depending on foil manipulation, to rhyme-based strategies.

The results for one-phoneme onset overlap were also as predicted. Most authors agree that previous demonstrations of facilitation when primes and targets shared their first phoneme were due to expectancy strategies and not to automatic processes. In line with this view, we observed expectancy effects due to one-phoneme onset overlap at all ISIs and no relatedness effects. Two aspects of these results should be noted. First, why were there expectancy effects even at the 50-msec ISI, when these effects emerged only at the 2,000-msec ISI in the rhyme overlap subexperiment? We explain this as follows: There are rapid expectancy effects with single onset phonemes because such expectancies are relatively easy to apply (they involve only single phonemes) and because the primes could be effectively used to predict how the targets would begin. The listeners could rapidly make use of phonological expectancies to bias their lexical decisions, since overlapping phonological information appeared in onset position. The effect of expectancy also tended to become stronger at longer ISIs, since the listeners had more time to apply an expectancy strategy. Second, why was there no evidence of automatic facilitation with one-phoneme onset overlap, when actual phonological overlap of rimes did produce facilitation? The most plausible answer is that there was simply not enough overlap to generate a detectable facilitatory effect. The activation of the prelexical representation of the initial sound of the prime should benefit processing of the target, just as when a three-phoneme rime is repeated, but it is reasonable to assume that the benefit for single-phoneme overlap will be smaller than that for multiple-phoneme overlap. In the one-phoneme overlap case, then, a single onset consonant was not enough phonological overlap to produce automatic facilitation but was sufficient for listeners to make use of phonological expectancies to bias their lexical decisions and produce reliable expectancybased effects even at the shortest ISIs.

As we have already discussed, there was evidence of both expectancy-based strategies and automatic facilitation in the three-phoneme onset overlap conditions. We suggested that listeners developed a strategy of responding no when targets mismatched with the expectancy set up by the prime (i.e., in UU trials, such as knak-tros), and a strategy of responding yes when targets matched expectancies (i.e., in ER trials [e.g., knak-knap] and in EU trials [e.g., trog-slim]). Furthermore, in UR trials, such as trog-trom, the facilitation due to overlapping phonemes appears to have counteracted the inhibition due to the mismatch in expectancies. The pattern of results for three-phoneme onset overlap, therefore, was different from that for rhyme overlap. Nevertheless, it appears that both sets of results are consistent with the idea that there are both automatic and controlled components in phonological priming. The reason for the differences between overlap conditions is simply that the position of the overlap differed. Overlap position should not influence automatic prelexical facilitation, since the same number of phonemes are reactivated on related trials in both the rhyme and the three-phoneme onset overlap conditions. In contrast, overlap position does have a strong effect on the nature of the strategies that are developed: Onset overlap can be used to predict the onset of the target before the target is heard, whereas rhyme overlap cannot; furthermore, rhymes are more salient than alliterations. Thus, although the instructions and training on expectancies were the same in both subexperiments, the listeners developed different response strategies in reaction to the kind of overlap they encountered.

In the introduction, we discussed evidence of inhibition arising from multiple-phoneme onset overlap. It has been argued that this inhibition is due to the automatic mechanism of lexical competition (e.g., Slowiaczek \& Hamburger, 1992): If the prime sweep, for example, is reactivated by the target sweet, sweep will compete strongly with sweet, delaying recognition of sweet. We pointed out, however, that the pattern of previous results was inconsistent. Some studies showed a significant inhibitory effect (Goldinger, 1999; Hamburger \& Slowiaczek, 1996, 1999; Monsell \& Hirsh, 1998; Pitt \& Shoaf, 2002; Radeau et al., 1989; Slowiaczek \& Hamburger, 1992; Slowiaczek \& Pisoni, 1986), but others did not (Praamstra et al., 1994; Radeau et al., 1995). In addition, it has been suggested that such inhibitory effects, when found, may instead be due to expectancy effects (Pitt \& Shoaf, 2002). One of our present goals for three-phoneme onset overlap was, therefore, to try to cleave the expectancy effects from the automatic effects (whether facilitatory or inhibitory). We found in our experiments evidence of automatic activation decreasing over time and strategic effects increasing over time. The complex interaction of these effects observed in the present data may be able to help explain the inconsistent pattern of results found in the literature.

These findings do not mean, however, that there are no automatic competition effects with multiple-phoneme onset overlap. Dufour and Peereman (2003) have recently argued that inhibitory effects should be larger when the prime and the target have few competitors than when they have many competitors, because the reactivated prime will compete more effectively with the target when there 
are fewer other words in the competition process. Their results, from a study in French, were in line with this prediction. Word pairs such as beurre-boeuf("butter-beef"), which come from sparse lexical neighborhoods (i.e., there are few words that begin in the same way), produced a significant inhibitory priming effect. Dufour and Peereman found no inhibition, however, for word pairs that come from dense neighborhoods. Note also that these findings challenge the suggestion that these inhibitory effects are due to the surprise caused by UR trials (Pitt \& Shoaf, 2002). Such an expectancy effect should not vary as a function of lexical neighborhood density. One reason, therefore, why we may have failed to observe an inhibitory effect is that the targets in our experiment had many competitors. By necessity, our targets all came from dense neighborhoods: In order to construct the conditions of the experiment, we had to choose large sets of items that began in the same way. An expectancy after a given prime could be trained, and then tested, only if there were multiple words available that all began in the same way as that prime. It appears to be impossible to use the Neely (1977) design to test for inhibitory onset overlap effects in sparse lexical neighborhoods.

Given our results, however, one can also ask why Dufour and Peereman (2003) failed to detect facilitation. One account might be that since onset overlap in their study was only two phonemes, the automatic facilitation was minimal. But Radeau et al. (1995), for example, have observed facilitation with two-phoneme overlap in final position. Another account might be that for their manycompetitor words, facilitation and inhibition cancel each other out, whereas for their few-competitor words, inhibition dominates. But if so, we ought not to have observed facilitation with our many-competitor words. A more likely explanation, therefore, is that strategic processing also influenced performance in the French study. On this view, the net effect of facilitation and weak inhibition with many-competitor words is facilitation (as observed in the present study), but this facilitation can be blocked by some kind of strategy. We suggested earlier that the reason why Norris et al. (2002) failed to detect rhyme-based facilitation in lexical decision in the presence of foils may have been that the foils induced a checking strategy. Similarly, it is possible that the participants in Dufour and Peereman's study detected the overlapping prime-target pairs and, thus, adopted a strategy of checking whether the targets began in the same way as the primes. This could have counteracted any net automatic facilitatory effect in the many-competitor condition but may not have removed all of the net automatic inhibitory effect in the few-competitor condition.

The general message here is that for multiple-phoneme onset overlap conditions, three different factors are at work: automatic prelexical facilitation, lexical competition, and strategic processes (and there is, of course, more than one possible kind of strategy that listeners could use). We suggest that it is the complex interplay of these factors that has led to the confusing picture in the previous literature on multiple-phoneme overlap. As Dufour and
Peereman (2003) have shown, automatic prelexical facilitation can be modulated through manipulating such factors as lexical neighborhood density. Also, the nature of the task (Radeau et al., 1989), the proportion of related trials (Hamburger \& Slowiaczek, 1996), and the position of those trials in the experiment (Pitt \& Shoaf, 2002) can all influence the kind of strategies listeners employ. The Neely (1977) procedure adopted here appears to be one way to control for listener strategies - namely, by explicitly manipulating them within the context of the experiment. Given the effects of strategies and lexical competition in earlier studies, it has not previously been possible to observe a facilitatory effect of multiple-phoneme onset overlap. But there really should be such an effect if, as many authors have argued, the facilitation observed with rhyme overlap is due to the repeated activation of prelexical representations; this benefit should not depend on the position of the overlap. The Neely design made it possible to view this facilitation.

We interpret our results as evidence for models of spoken-word recognition in which there is an abstract prelexical level of processing. Several models, including TRACE (McClelland \& Elman, 1986), Shortlist (Norris, 1994), the neighborhood activation model (Luce \& Pisoni, 1998), and the distributed cohort model (Gaskell \& Marslen-Wilson, 1997), assume that there is an intermediate stage of processing that mediates between lowlevel auditory processing and the mental lexicon. In other models, however, no such prelexical stage of processing is specified (e.g., the lexical access from spectra model of Klatt, 1979, and the episodic model of Goldinger, 1998a). The evidence on automatic facilitatory priming effects due to phonological overlap challenges the latter models. As we described in the introduction, it has been shown that the facilitation due to rhyme overlap arises only when both primes and targets are in the auditory modality (Dumay et al., 2001; Spinelli et al., 2001) and that this facilitation does not depend on the lexical status of the prime (Dumay et al., 2001; Monsell \& Hirsh, 1998; Slowiaczek et al., 2000). Such findings support our claim that the facilitation is due to prelexical processes. If this claim is correct, however, it ought to be possible to observe facilitation with multiple-phoneme overlap irrespective of position of the overlap. It has been a problem in the previous phonological priming literature that such facilitation has not been found. The demonstration of facilitation in the three-phoneme onset overlap subexperiment solves this problem and, therefore, reinforces the earlier interpretation of automatic facilitatory effects in phonological priming. Although the different models with a prelexical level make different assumptions about the nature of prelexical representations, our results do not speak to this issue. The facilitation could be due to repeated activation of, for example, featural, phonemic, or syllabic representations. Nevertheless, our results do suggest that there is some kind of abstract prelexical level of processing.

We began this article by making the distinction between automatic and controlled processes in speech perception. In order to understand phonological priming, it is evi- 
dently essential to make this distinction. It is possible to draw conclusions about the nature of the automatic processes in the speech perception system only if it can be established that effects are not due to task-specific strategies. Although this has been our focus, it is important to emphasize that expectancy strategies (or other kinds of task-related biases) are not simply nuisance variables that have to be controlled. The success of the present paradigm - the fact that listeners were indeed able to learn to use phonological expectancies to shape their lexical decision responses - demonstrates that listeners can do a lot to modulate how they respond in different listening situations. If they can do so in a laboratory experiment, they can do so in everyday listening too. Controlled processes are thus very much a part of speech perception. Theories of spoken-word recognition must, therefore, seek to account not only for the automatic components that are involved in listening to speech, but also for the ability of listeners to manipulate the speech that they are hearing and to respond to speech in a situation-specific manner. Nevertheless, in order to develop such theories, it is necessary to cleave these controlled processes from the automatic components of the speech recognition system.

\section{REFERENCES}

BaAyen, R. H., Piepenbrock, R., \& van Rijn, H. (1993). The CELEX Lexical Database [CD-ROM]. Philadelphia: University of Pennsylvania, Linguistic Data Consortium.

Balota, D. A., \& Chumbley, J. I. (1984). Are lexical decisions a good measure of lexical access? The role of frequency in the neglected decision stage. Journal of Experimental Psychology: Human Perception \& Performance, 10, 340-357.

Burton, M., Jongman, A., \& Sereno, J. (1996). Phonological and orthographic priming effects in auditory and visual word recognition. In W. Ham \& L. Lavoie (Eds.), Working papers of the Cornell Phonetics Laboratory (Vol. 11, pp. 17-41). Ithaca, NY: Cornell University, Department of Linguistics.

Dufour, S., \& PeEreman, R. (2003). Inhibitory priming effects in auditory word recognition: When the target's competitors conflict with the prime. Cognition, 88, B33-B44.

Dumay, N., Benraïss, A., Barriol, B., Colin, C., Radeau, M., \& Besson, M. (2001). Behavioral and electrophysiological study of phonological priming between bisyllabic spoken words. Journal of Cognitive Neuroscience, 13, 121-143.

EMMOREY, K. D. (1989). Auditory morphological priming in the lexicon. Language \& Cognitive Processes, 4, 73-92.

Gaskell, M. G., \& MarsLen-Wilson, W. D. (1997). Integrating form and meaning: A distributed model of speech perception. Language $\&$ Cognitive Processes, 12, 613-656.

Goldinger, S. D. (1998a). Echoes of echoes? An episodic theory of lexical access. Psychological Review, 105, 251-279.

Goldinger, S. D. (1998b). Signal detection comparisons of phonemic and phonetic priming: The flexible-bias problem. Perception \& Psychophysics, 60, 952-965.

Goldinger, S. D. (1999). Only the Shadower knows: Comment on Hamburger and Slowiaczek (1996). Psychonomic Bulletin \& Review, 6, 347-351.

Goldinger, S. D., Luce, P. A., Pisoni, D. B., \& Marcario, J. K. (1992). Form-based priming in spoken word recognition: The roles of competition and bias. Journal of Experimental Psychology: Learning, Memory, \& Cognition, 18, 1211-1238.

Hamburger, M., \& SlowiacZeK, L. M. (1996). Phonological priming reflects lexical competition. Psychonomic Bulletin \& Review, 3, 520-525.

Hamburger, M., \& SlowiaczeK, L. M. (1999). On the role of bias in dissociated phonological priming effects: A reply to Goldinger (1999). Psychonomic Bulletin \& Review, 6, 352-355.
Hillinger, M. L. (1980). Priming effects with phonemically similar words: The encoding-bias hypothesis reconsidered. Memory \& Cognition, 8, 115-123.

JAKIMIK, J., Cole, R. A., \& RudNICKY, A. I. (1985). Sound and spelling in spoken word recognition. Journal of Memory \& Language, 24, 165-178.

KLATT, D. H. (1979). Speech perception: A model of acoustic-phonetic analysis and lexical access. Journal of Phonetics, 7, 279-312.

Luce, P. A., \& Pisoni, D. B. (1998). Recognizing spoken words: The neighborhood activation model. Ear \& Hearing, 19, 1-36.

McClelland, J. L., \& Elman, J. L. (1986). The TRACE model of speech perception. Cognitive Psychology, 10, 1-86.

Meyer, D. E., \& SchVAneveldT, R. W. (1971). Facilitation in recognizing pairs of words: Evidence of a dependence between retrieval operations. Journal of Experimental Psychology, 90, 227-234.

Meyer, D. E., Schvaneveldt, R. W., \& Ruddy, M. G. (1974). Functions of graphemic and phonemic codes in visual word-recognition. Memory \& Cognition, 2, 309-321.

Monsell, S., \& Hirsh, K. W. (1998). Competitor priming in spoken word recognition. Journal of Experimental Psychology: Learning, Memory, \& Cognition, 24, 1495-1520.

NeELY, J. H. (1977). Semantic priming and retrieval from lexical memory: Roles of inhibitionless spreading activation and limited-capacity attention. Journal of Experimental Psychology: General, 106, 226-254.

Norris, D. (1994). Shortlist: A connectionist model of continuous speech recognition. Cognition, 52, 189-234.

Norris, D., McQueen, J. M., \& Cutler, A. (2002). Bias effects in facilitatory phonological priming. Memory \& Cognition, 30, 399-411.

PitT, M. A., \& ShOAF, L. (2002). Revisiting bias effects in word-initial phonological priming. Journal of Experimental Psychology: Human Perception \& Performance, 28, 1120-1130.

PosNer, M. I., \& SNYDER, C. R. R. (1975). Facilitation and inhibition in the processing of signals. In P. M. A. Rabbitt \& S. Dornic (Eds.), Attention and performance $V$ (pp. 669-682). London: Academic Press.

Praamstra, P., Meyer, A. S., \& Levelt, W. J. M. (1994). Neurophysiological manifestations of phonological processing: Latency variation of a negative ERP component time-locked to phonological mismatch. Journal of Cognitive Neuroscience, 6, 204-219.

Radeau, M., Besson, M., Fonteneau, E., \& Castro, S. L. (1998). Semantic, repetition, and rime priming between spoken words: Behavioral and electrophysiological evidence. Biological Psychology, 48, 183-204.

Radeau, M., Morais, J., \& Dewier, A. (1989). Phonological priming in spoken word recognition: Task effects. Memory \& Cognition, 17, 525-535.

Radeau, M., Morais, J., \& Seguí, J. (1995). Phonological priming between monosyllabic spoken words. Journal of Experimental Psychology: Human Perception \& Performance, 21, 1297-1311.

SCHNEIDER, W., \& ShIFfrin, R. M. (1977). Controlled and automatic human information processing: I. Detection, search, and attention. Psychological Review, 84, 1-66.

SchVANEVELDt, R. W., \& Meyer, D. E. (1973). Retrieval and comparison processes in semantic memory. In S. Kornblum (Ed.), Attention and performance $I V$ (pp. 395-409). New York: Academic Press.

SHIFFrIN, R. M., \& SCHNEIDER, W. (1977). Controlled and automatic human information processing: II. Perceptual learning, automatic attending, and a general theory. Psychological Review, 84, 127-190.

Slowiaczek, L. M., \& Hamburger, M. (1992). Prelexical facilitation and lexical interference in auditory word recognition. Journal of Experimental Psychology: Learning, Memory, \& Cognition, 18, 1239-1250.

SlowiaczeK, L. M., McQueen, J. M., Soltano, E. G., \& Lynch, M. (2000). Phonological representations in prelexical speech processing: Evidence from form-based priming. Journal of Memory \& Language, 43, 530-560.

SlowiaczeK, L. M., Nusbaum, H. C., \& Pisoni, D. B. (1987). Phonological priming in auditory word recognition. Journal of Experimental Psychology: Learning, Memory, \& Cognition, 13, 64-75.

SlowiaczeK, L. M., \& Pisoni, D. B. (1986). Effects of phonological similarity on priming in auditory lexical decision. Memory \& Cognition, 14, 230-237.

Spinelli, E., Seguí, J., \& Radeau, M. (2001). Phonological priming in spoken word recognition with bisyllabic targets. Language \& Cognitive Processes, 16, 367-392. 
Titone, D., \& Connine, C. M. (1997). Syllabification strategies in spoken word processing: Evidence from phonological priming. Psychological Research, 60, 251-263.

\section{NOTE}

1. Another possible explanation for the results in this subexperiment, for which we thank an anonymous reviewer, is that the participants may have noticed that when there was a phonological relationship between the prime and the target, the target was always a word. They could, therefore, have developed a strategy of responding yes whenever they detected phonological overlap. In combination with the expectancy-based strategy encouraged by the instructions, this overlap-based strategy could account for the results. Performance in the EU trials would benefit from the expectancy strategy, that in the UR trials from the overlap strategy, and that in the ER trials from both strategies, making all three types of trial easier than UU trials. We cannot definitively rule this possibility out, but we prefer our proposed explanation for three reasons. First, the overlapbased strategy makes the wrong predictions for rhyme overlap. This kind of overlap would, if anything, be noticed more easily than three-phoneme onset overlap, given the salience of rhyme, but a different pattern of results was observed in the rhyme-overlap subexperiment than the overlap strategy predicts. Second, there is evidence within the three-phoneme onset overlap subexperiment that the relatedness effect gets weaker at longer ISIs. This finding is consistent with the account in which the relatedness effect is due to an automatic process but is inconsistent with a strategy-based explanation. Third, we think that it is unlikely that the participants would notice that form overlap was present only when the targets were words and that, even if they did, they would be unlikely to develop an overlap-based response strategy. This is because there were just as many trials with word targets in which there was no phonological overlap as trials with word targets that did overlap with their primes.

\section{APPENDIX}

\section{A. Rhyme Overlap}

0. Initial Practice (art/ump/ens) Block

Prime Word Targets

start dart, kart, flard, mart, part, zwart

dump lens, flens, plens, grens, wens, pens

$\mathrm{xxx} / \mathrm{nu} \quad$ fans, mens, hens, hart, kwart, smart

1. ank/ocht/ips Block

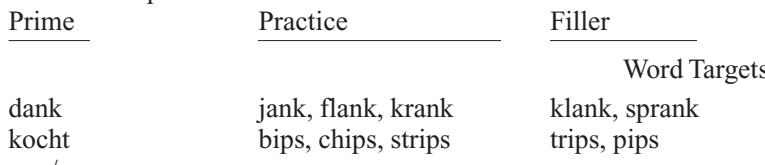

\begin{tabular}{|c|c|c|}
\hline $\begin{array}{l}\text { dank } \\
\text { kocht } \\
\text { xxx/nu }\end{array}$ & $\begin{array}{l}\text { horm, mugt, flunt } \\
\text { pleems, dwalm, psarf }\end{array}$ & $\begin{array}{l}\quad \text { Nonword Targets } \\
\text { vuigt } \\
\text { dulp } \\
\text { grept, hent }\end{array}$ \\
\hline $\begin{array}{l}\text { 2. ist/amp/enk Block } \\
\text { Prime }\end{array}$ & Practice & Filler \\
\hline $\begin{array}{l}\text { gist } \\
\text { damp } \\
x x x / n u\end{array}$ & $\begin{array}{l}\text { twist, sist, rist } \\
\text { yank, slenk, krenk }\end{array}$ & $\begin{array}{l}\quad \text { Word Targets } \\
\text { kist, vist } \\
\text { wenk, zwenk }\end{array}$ \\
\hline $\begin{array}{l}\text { gist } \\
\text { damp } \\
\mathrm{xxx} / \mathrm{nu}\end{array}$ & $\begin{array}{l}\text { fielk, roemp, krelf } \\
\text { slerf, klons, bolf }\end{array}$ & $\begin{array}{l}\quad \text { Nonword Targets } \\
\text { bierf } \\
\text { brent } \\
\text { tuurs, serp }\end{array}$ \\
\hline $\begin{array}{l}\text { 3. ans/erk/icht Block } \\
\text { Prime }\end{array}$ & Practice & Filler \\
\hline $\begin{array}{l}\text { glans } \\
\text { merk } \\
\text { xxx/nu }\end{array}$ & $\begin{array}{l}\text { zwans, trance, mans } \\
\text { wicht, sticht, nicht }\end{array}$ & $\begin{array}{l}\text { Word Targets } \\
\text { kans, thans } \\
\text { licht, zicht }\end{array}$ \\
\hline $\begin{array}{l}\text { glans } \\
\text { merk } \\
\text { xxx/nu }\end{array}$ & $\begin{array}{l}\text { himp, koft, hieft } \\
\text { plont, slaft, naps } \\
\text { nums, waark }\end{array}$ & $\begin{array}{l}\text { Nonword Targets } \\
\text { birt } \\
\text { polp }\end{array}$ \\
\hline
\end{tabular}

Nonword Targets

nift, hoerf, baft, frast, snark, kriens dwomp, frilm, delm, zielk, jelk, niemp spets, splink, gols, kroeft, pleifs, schomp

Experimental

bank, plank, bocht, zocht

slips, tips, tocht, mocht

blank, rank, vocht, pocht, gips, clips

vurp, woft, twols, prelf, werg

hoons, sulf, zwins, nals, slimp

seurk, twoens, tats, sielk

Experimental

mist, list, lamp, stamp

schenk, tank, ramp, kamp

grist, slist, schamp, klamp, denk, drenk

berf, jarf, klarp, renk, drelp

foels, negt, rient, jest, vrols

spont, stoogt, galp, fuuls

Experimental

dans, krans, kerk, sterk

plicht, dicht, berk, werk

schans, gans, klerk, perk, richt, jicht

zaapt, dwekt, kimp, remp, peft

hilt, leens, plost, schaust, weut

baams, steurm, troeks, zwars 


\section{APPENDIX (Continued)}

\begin{tabular}{|c|c|}
\hline $\begin{array}{l}\text { 4. onk/est/alm Block } \\
\text { Prime }\end{array}$ & Practice \\
\hline $\begin{array}{l}\text { honk } \\
\text { nest } \\
\text { xxx/nu }\end{array}$ & $\begin{array}{l}\text { bonk, dronk, ronk } \\
\text { palm, talm, halm }\end{array}$ \\
\hline $\begin{array}{l}\text { honk } \\
\text { nest } \\
\text { xxx/nu }\end{array}$ & $\begin{array}{l}\text { moeps, darp, noers } \\
\text { bulp, pilk, barp }\end{array}$ \\
\hline $\begin{array}{l}\text { 5. aart/alk/ons Block } \\
\text { Prime }\end{array}$ & Practice \\
\hline $\begin{array}{l}\text { maart } \\
\text { valk } \\
\mathrm{xxx} / \mathrm{nu}\end{array}$ & $\begin{array}{l}\text { waard, haard, gaard } \\
\text { gons, frons, tons }\end{array}$ \\
\hline $\begin{array}{l}\text { maart } \\
\text { valk } \\
\text { xxx/nu }\end{array}$ & $\begin{array}{l}\text { poks, giels, bielp } \\
\text { hurs, mips, twegt }\end{array}$ \\
\hline $\begin{array}{l}\text { 6. acht/omp/ink Block } \\
\text { Prime }\end{array}$ & Practice \\
\hline $\begin{array}{l}\text { nacht } \\
\text { homp } \\
\text { xxx/nu }\end{array}$ & $\begin{array}{l}\text { zacht, slacht, klacht } \\
\text { vink, pink, blink }\end{array}$ \\
\hline $\begin{array}{l}\text { nacht } \\
\text { homp } \\
\text { xxx/nu }\end{array}$ & $\begin{array}{l}\text { gieps, rils, smirk } \\
\text { tunk, vruns, sank }\end{array}$ \\
\hline
\end{tabular}

$\frac{\text { Filler }}{\text { Word Targets }}$
pronk, stronk
zalm, kalm

\section{Nonword Targets}

brols

bromp

wemp, hiens

Filler

Word Targets

baard, taart

plons, bons

Nonword Targets

vlieps

beems

korg, plift

Filler

\section{Word Targets}

kracht, gracht

klink, zink

Nonword Targets

plurm

glakt

scheup, dwoelt
Experimental

vonk, klonk, mest, vest

galm, psalm, pest, best

blonk, stonk, rest, test, walm, schalm

seft, slamt, merp, pams, sparp

flark, gamp, vimp, rilf, wirm

sterp, plenk, nieps, helk

Experimental

paard, zwaard, kalk, zwalk

spons, dons, spalk, balk

staart, klaart, schalk, talk, brons, slons

vliens, slens, wups, neeps, schelk gromp, diest, twerm, troens, spocht

laarn, mert, drins, schast

Experimental

jacht, macht, lomp, stomp

flink, drink, klomp, pomp

wacht, pracht, plomp, romp, hink, stink

kirk, felf, lenk, moops, bauks slart, glicht, tralk, jeft, stuulf tems, blark, loenk, grolp

\section{B. One-Phoneme Onset Overlap}

0. Initial Practice (f/sh/j) Block

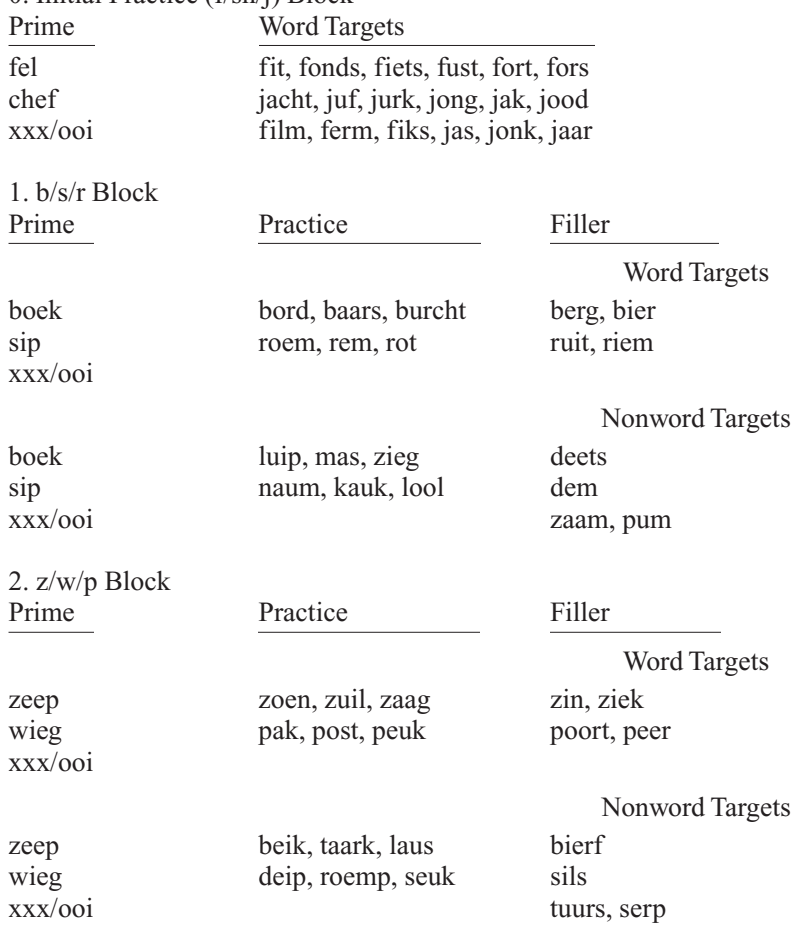

Nonword Targets

zos, dint, kuun, neert, huip, veus zaapt, veim, taat, soog, renk, nim siel, peis, lin, sal, goen, diek

Experimental

big, been, suf, sas rang, raam, sof, cel bal, beurs, sap, sok, ring, rijp

vus, woft, taaf, puig, hoons fien, huul, vuigt, weuk, keuk mif, giem, lut, hoels

Experimental

zoon, zand, wijs, wens poes, pen, worst, warm zon, zalf, wals, woest, pit, punt

meuf, juun, biem, rien, saals foels, hent, neeps, dits, veet teent, negt, galp, fuuls 
APPENDIX (Continued)

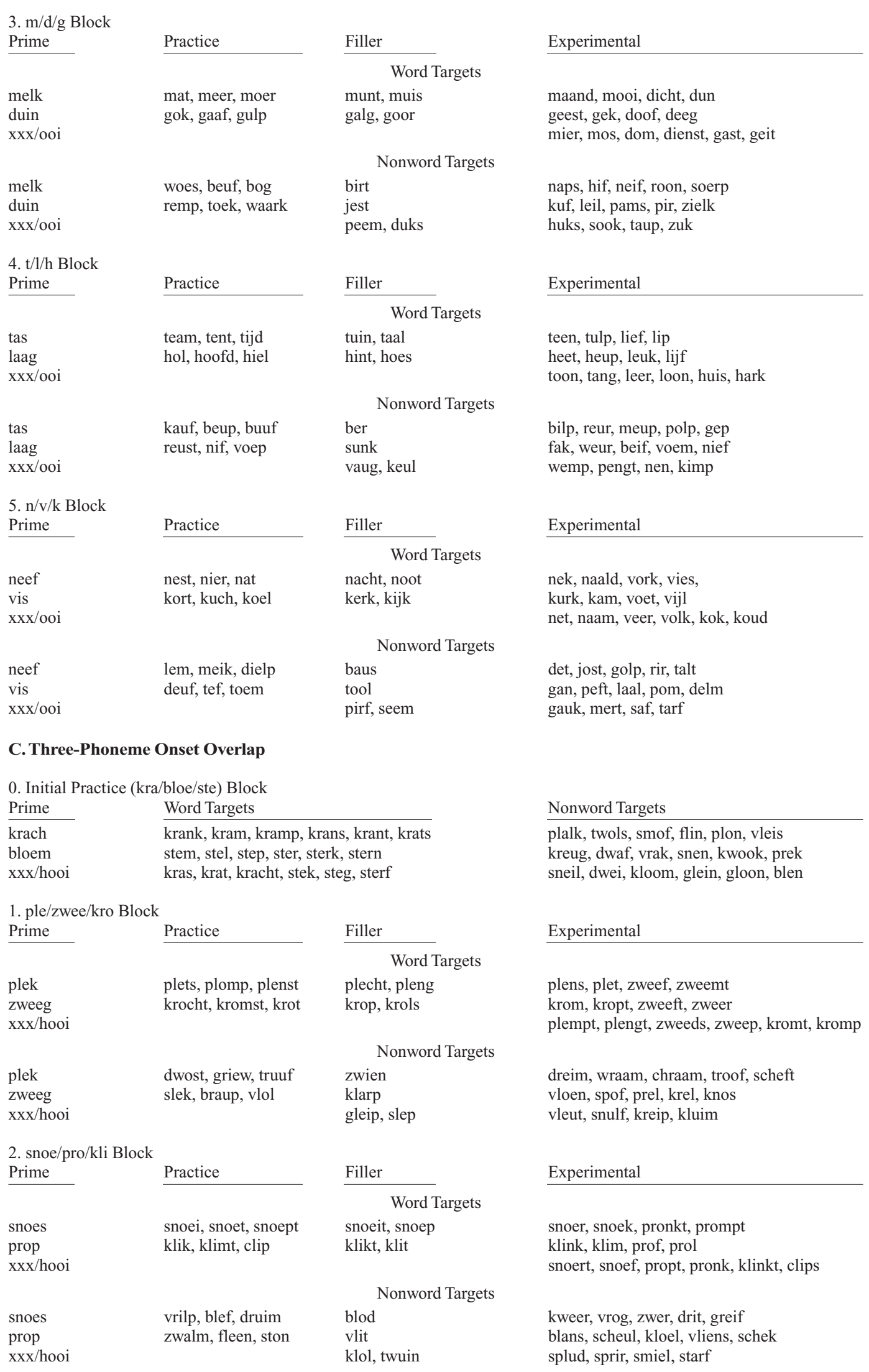


APPENDIX (Continued)

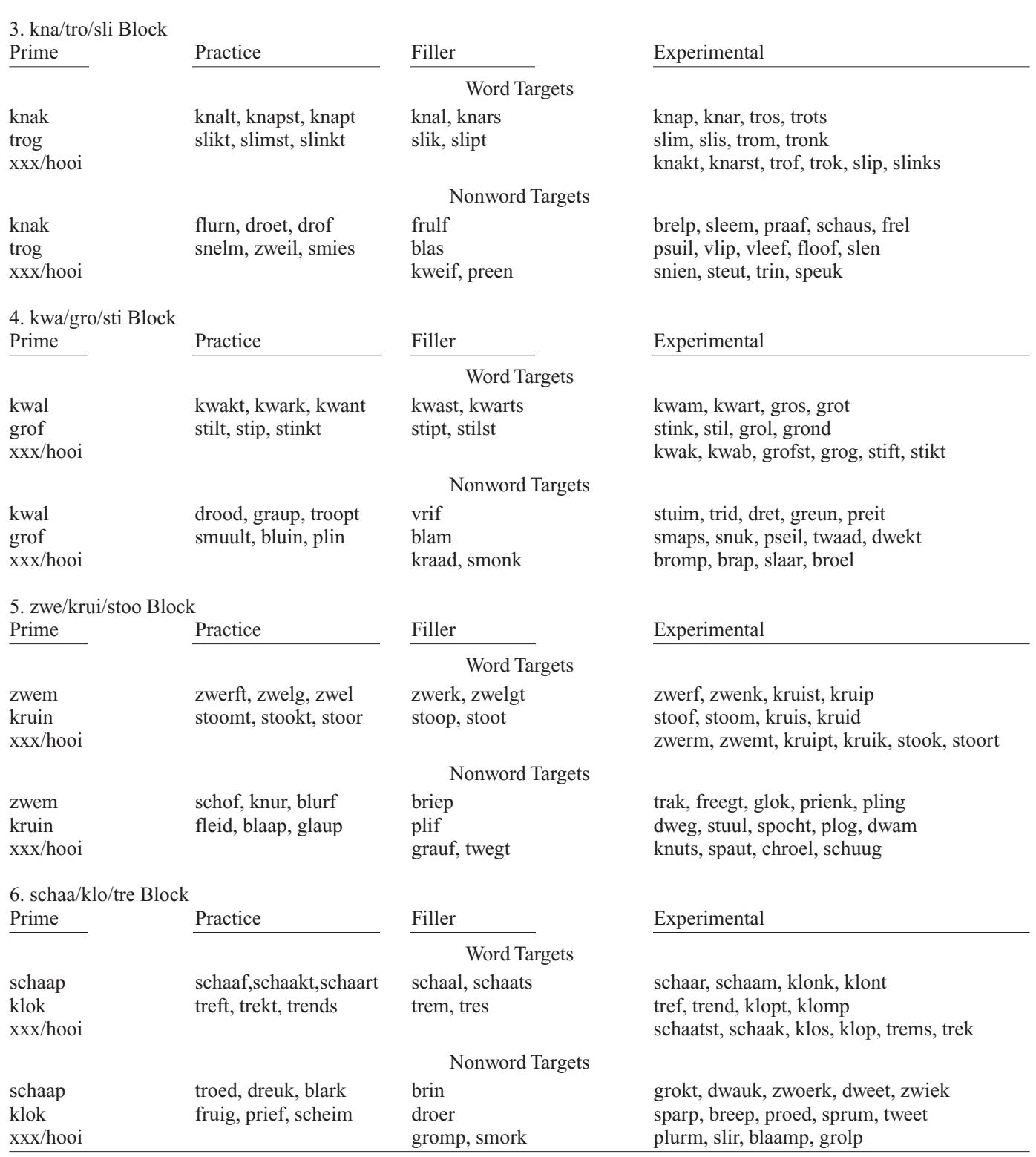

(Manuscript received October 16, 2003;

revision accepted for publication November 18, 2004.) 